June 2013

\title{
Rheological Properties of Alkaline Activated Fly Ash used in Jet Grouting Applications
}

\author{
*Nuno Cristelo; **Edgar Soares; ***Ivo Rosa; ****Tiago Miranda; \\ ****Daniel V. Oliveira; ****Rui A. Silva; ***Ana Chaves \\ * CEC, Faculty of Engineering of University of Porto, Porto, Portugal \\ ECT, University of Trás-os-Montes e Alto Douro5000-801 Vila Real, Portugal \\ (tel) + $351966193212($ fax $)+351259350356$ \\ ncristel@utad.pt \\ ** University of Trás-os-Montes e Alto Douro, Vila Real, Portugal \\ *** Teixeira Duarte, Porto Salvo, Portugal \\ ***** ISISE, University of Minho, Guimarães, Portugal
}


Abstract

The application of alkaline activated fly ash to soil stabilisation has been recently studied, and although the structural behaviour was adequate, some concerns were raised regarding its apparent viscosity, which proved to be an important issue in jet grouting applications. Therefore, this paper deals with the experimental study of rheology of alkaline activated fly ash - based grouts, namely with: setting time of the freshly mixed grout; fluidity; capillary absorption; shrinkage and expansion behaviour; mass variation during the curing process and density. In order to establish some correlation points with structural performance, uniaxial compression strength (UCS) at 28 days curing was also determined. Six different grout compositions, defined based on $\mathrm{Na}_{2} \mathrm{O}$ (alkali) / ash and activator / ash ratios, were analysed. The activator was composed of sodium silicate and two different sodium hydroxide concentrations: 10.0 and 12.5 molal. Results show that the fluidity of the grouts correlate very well with UCS, with an increase of the former resulting in a decrease in the latter, which is a concern in jet grouting applications since this parameter controls the velocity of the grout at the nozzle and the soil / grout mixing capability. In terms of porosity, this type of material seems to be less porous than cement-based grouts. However, drying shrinkage values obtained were in general higher than usual for concrete, which is in accordance with results obtained by other researchers.

Keywords: Fly Ash; Alkaline Activation; Rheology; Jet Grouting; Soil Stabilisation 


\title{
1. Introduction
}

The reasons for investigating the use of alternative binders for soil stabilisation are not only technical (there will always be good reasons for improving the performance of any given construction material) but also environmental, due to the high levels of $\mathrm{CO}_{2}$ released during cement production, estimated at $7 \%$ of the total anthropogenic $\mathrm{CO}_{2}$ [1]. Regarding the environmental issues associated with alkaline activated fly ash, it is important to note that all the materials involved are industrial by-products, which therefore do not produce any additional hazard. This includes the activator constituents and the fly ash. In terms of technical performance, the advantages of alkali-based products over cement include not only the mechanical behaviour (i.e. strength and deformability properties) but also durability, which is of special concern when dealing with buried structures like jet grouting columns (the chemical vulnerability of Portland cement to sulphates present in the ground is well known [2]). Also of significance when using alternative binders such as those here presented is the possibility to use waste materials in new constructions, reducing the total volume that needs to be disposed of in ever increasing landfills.

\begin{abstract}
Alkaline activation of fly ash was recently applied to deep soft soil stabilisation using jet grouting [3]. The large spectrum of applications, combined with its relatively low cost when compared with deep mixing techniques, made jet grouting the best choice to develop a new binder based on the alkaline activation technique. Although it was concluded that the application is viable and effective when compared with Portland cement grouts, several of the jet grouting columns, executed during the mentioned study using different jet parameters, were not successful. It was considered that the reason for this was the inadequate rheological properties of the fly ash - based alkaline activated grout, after a comparison of the viscosity values between the fly ash grout and a cement grout revealed that the former was significantly
\end{abstract}


more viscous than the latter [4]. The present paper presents the results obtained from a and discusses those results in light of one particular application: soil stabilisation with jet grouting. The experimental plan was designed after analysing the mechanical performance of alkaline activated fly ash binders on soil stabilisation (personal communication), and deals with the rheological behaviour of the most effective ash/activator combinations obtained during that study. Therefore, the aim of this study was to characterise the rheology of the mixtures, and to establish a correlation between these and the UCS values. It is believed that such knowledge is essential to effectively design injection grouts for deep soil stabilisation, capable of delivering mechanically sound results, but specially to be performing from a rheological view. A sodium based activator was used, with two different concentrations and different activator / ash and $\mathrm{Na}_{2} \mathrm{O} /$ ash ratios. To help establish some references and set the parameters for the tests performed, and since very few scientific documents were yet published regarding soil stabilisation with alkaline activation (including specific standards), cement-based standards were used [5]. The experimental work included the evaluation of the unconfined compression strength at 28 days curing; mineralogical X-ray diffraction (XRD), scanning electron microscopy (SEM) and energy dispersive spectroscopy (EDS) analysis of the original fly ash and one of the fly ash / activator binders; setting time of the freshly mixed grout; fluidity; capillary absorption; shrinkage - expansion (including mass variation) and density.

Briefly, alkaline activation can be described as a reaction between amorphous alumina and silica and alkali ions, usually sodium $(\mathrm{Na})$ or potassium $(\mathrm{K})$, or alkali earth ions like calcium (Ca). The first step is the breaking of the covalent Si-O-Si, Al-O-Al and Al-O-Si bonds from the vitreous phase, creating a supersaturated aluminosilicate solution of monomers that precipitate and form a gel of new 3D structures through polycondensation. In these new 
structures the silica $\left(\mathrm{SiO}_{2}\right)$ and alumina $\left(\mathrm{AlO}_{4}\right)$ tetraedrics interconnect and share the oxygen (O) ions. The rheological properties of this gel have yet to be completely characterised, especially since more variables are involved in the design of alkali activated materials than cement-based materials, which only increases the range of possible fresh state behaviours that needs to be predicted.

\section{Jet grouting}

The jet grouting technique was first used in 1962 by a British company to form impermeable curtains in sandy soils; and basically consisted in excavating a hole in the ground using a radial and vertical water jet at high pressure [6]. When the desired depth was achieved, the water was substituted by a chemical grout and the rod was pulled. Later in the sixties, the method was developed a bit further in Japan, when the rod was rotated as it was lifted, using it to actually improve soft soils. In 1973 an Italian company substituted the chemical grout with a cement grout and used injection pressures of $35 \mathrm{MPa}$ and flow rates between 100 and 200 $1 /$ min. The physical process of jet grouting comprises one of two possible procedures. In the first case the soil is fractured and mixed in place with a cement grout. In the second case the soil is partially removed and replaced by the grout. The overall process features the following mechanisms:

- Cut - the original soil structure is broken and soil particles disperse due to the action of high speed horizontal jets.

- Mixing and substitution - some of the soil particles are substituted and the remaining are mixed with the injected grout. 
- Cementation - soil particles are glued together by the increasing viscosity of the grout, forming a solid body.

Three types of jet can be used: single (grout), double (grout + air) and triple fluid jet grouting (grout + air + water). Operating conditions and requirements on site, in terms of available space, construction stages and, more importantly, the type of soil to be treated, determine the choice of the most appropriate method. The process of building a column with the single system consists in the insertion of the drill rod, equipped with the nozzle bearing chamber, to the desired treatment depth by drilling, followed by lifting the rod string while on rotation and injecting the grout through the nozzles. At the same time, eroded spoil is being expelled at the top of the borehole. Percussion can also be used in more difficult soils, together with rotation, especially in cohesionless coarse grained soils and/or when boulders are found. Predrilling may be necessary to access the treatment zone, and can be complemented with a horizontal water jet when lifting the drilling in order to remould the bore surface soil so that increased homogenization is achieved. The borehole can be stabilized using a drilling mud during the procedure. If predrilling is not required, the borehole is made with or without the use of drilling fluid, usually water. Adjacent columns can intersect each other forming a panel or block. Probably the main advantage of jet grouting technique is its versatility. It can be used with proved efficiency, across the widest range of soil types, including silts and soft clays, although some authors express some doubts with respect to fine grained soils [7]. Column diameters between 0.3 and $1.4 \mathrm{~m}$ have been reported using the single system range, depending on the ground conditions and jet parameters, while for the same amount of grout injected, an increase of $30-70 \%$ can be achieved if a double system is used [8]. Figure 1 shows the range of compressive strength that can be achieved with different soils. 
Even the presence of groundwater does not have a significant capacity to compromise the final results. Special additives capable of accelerating the grout hardening can be used in case of seepage. The most significant operating parameters, in terms of influence on the mechanical and geometrical properties of the final column, are the following:

- Nozzle diameter;

- Nozzle number and position;

- $\quad$ Rotation speed $\left(\mathrm{V}_{\mathrm{r}}\right)$;

- $\quad$ Lifting speed $\left(\mathrm{V}_{1}\right)$;

- Injection pressure $(\mathrm{P})$;

- Grout flow rate (Q).

Each of these parameters has some level of influence on the remaining ones. For instance, the optimum nozzle diameter depends on the injection pressure since a lower top pressure makes it impossible to use larger nozzle diameters, because the increase in flow rate will not be sustained by the low capacity pump. Another example is the fact that a larger number of nozzles decrease efficiency, since it reduces the top pressure at the head. Therefore, the number and diameter of the nozzles exert a significant influence on the volume of grout injected, which is usually measured by the flow rate.

In the case of the single-fluid jet, the relatively low specific energy results in an increased difficulty for the grout to replace the soil. Therefore, the soil-grout mixing is the preferable process for column formation, which highlights the importance of the fluidity properties of 
An increase in the injection pressure correlates well with an increase on the diameter of the columns, especially for pressures up to $30 \mathrm{MPa}$, decreasing after that in both cohesive and coarse grained soils. The value of this parameter is usually set as a function of the equipment available on site, and the other parameters are adapted to the injection pressure. However, for the same parameter values, it is the rheology of the grout that will determine how far it can go inside a particular soil once it leaves the nozzles. If a high viscosity grout is used, even a high pressure injection cannot prevent a relatively short travel, creating small diameter columns with weak homogenisation levels between the soil and the grout. To minimise this behaviour it is necessary to decrease the rotation and/or the lifting speed, in order to increase the specific energy and the capacity of the jet to erode the soil around the axis of the column. This is of special concern when dealing with low permeability soils (cohesive soils), and as a consequence the grout starts to flow along the outer surface of the drill rod [8]. The efficiency of the set of parameter values chosen for a particular soil type / available equipment combination can be measured through the amount of grout per unit volume of soil, and if the grout has low fluidity, any attempt to increase the specific energy results in an increase in grout consumption.

\section{Methodology}




\title{
3.1 Materials characterisation
}

\begin{abstract}
The alkaline activator solution used was a combination of sodium silicate solution and sodium hydroxide solution, in a $1: 2$ ratio. Although several authors reported that maximum strength was obtained with the highest silicate : hydroxide ratios tested in their respective studies ([911]), a reduction of this ratio represents a decrease in the total cost of the mixture, if considering the total amount of alkali $\left(\mathrm{Na}_{2} \mathrm{O}\right)$ obtained from the two activator main constituents. The sodium silicate was originally in solution form, with a specific gravity of $1.464 \pm 0.021 \mathrm{~g} / \mathrm{cm}^{3}$ at $20^{\circ} \mathrm{C}$, a $\mathrm{SiO}_{2}: \mathrm{Na}_{2} \mathrm{O}$ mass ratio of approximately 2 and a $\mathrm{Na}_{2} \mathrm{O}$ concentration in the solution of $13.0 \%$. The sodium hydroxide was originally supplied in flake form with a specific gravity of 2.13 at $20^{\circ} \mathrm{C}$ and $98 \%$ purity, which was later dissolved in water to achieve concentrations of 10.0 and 12.5 molal.
\end{abstract}

The fly ash used is classified as type F, due to its low calcium content, and was obtained from a Portuguese thermo-electric plant. SEM micrographs revealed that the ash particles are mostly round (Figure 2), with average values of the particles general size described in Table 1. EDS analysis is summarized in Table 2, showing the presence of a total of $71 \%$ of silica and aluminum. XRD analysis showed the presence of quartz and mullite as the main minerals. The XRD equipment was a PANalyticalX'Pert Pro diffractometer, fitted with an X'Celerator. A secondary monochromator would have eliminated fluorescent scattering from the specimen, resulting in a good peak / background ratio for samples containing transition metals and rare earths. However, for this work the monochromator was unavailable, so the background scatter could be a little higher. The scans covered the range $5-70^{\circ} 2 \theta$, with a nominal step size of $0.033^{\circ} 2 \theta$ and time per step of 100 sec. Radiation is $\mathrm{Cu}$ K-alpha with a wavelength of $\lambda=1.54180$ A. Phase identification was carried out using the X'Pert accompanying software program High Score and the ICDD database, Sets 1-49 (1999). SEM 
analyses were performed on a FEI QUANTA - 400 electronic microscope, with an EDS system from EDAX attached. One of the mixtures was selected for SEM/EDS analysis, at 28 days curing.

Figure 2: SEM image of the original fly ash

Table 1: Statistical data regarding the fly ash particle's diameter

Table 2: Chemical composition of the fly ash

\subsection{Sample preparation}

A total of six different activator / ash ratios (or liquid / ash ratios) were tested (Table 3). Other authors used smaller activator / ash ratios $[12,13]$ when also studying alkaline activated fly ash. However, in the present case the analysed grouts are intended for injection in the soil, meaning that a higher liquid phase will be necessary.

Some mixtures were prepared with different $\mathrm{NaOH}$ concentrations and the same $\mathrm{Na}_{2} \mathrm{O} /$ ash ratio (GJG2 and GJG4; GJG8 and GJG10), to analyse the influence of such parameter. To maintain the $\mathrm{Na}_{2} \mathrm{O}$ / ash ratios at the same values in mixtures GJG2 and GJG4 (0.230) and mixtures GJG8 and GJG10 (0.155), it was necessary to change the activator / ash ratios.

Table 3: Characterisation of the mixtures analysed

The activator was prepared at least $24 \mathrm{~h}$ before being used, so that the temperature increase due to the exothermic reaction between the silicate and hydroxide was dissipated and the 
activator was back to room temperature, which in this case was $20 \pm 2^{\circ} \mathrm{C}$. To prepare the UCS test specimens, the fly ash and the activator were mixed for $10 \mathrm{~min}$ at a low speed, and the resulting grout (Figure 3) was cast into $150 \times 150 \times 150 \mathrm{~mm}^{3}$ moulds, which were then vibrated using a concrete vibratory table. Since the behaviour of the mixtures was that of a viscous fluid, no density control was used during the preparation of the samples. After the moulding process the upper face of these specimens was covered with cling film and the mould was stored in a room at constant temperature $\left(20^{\circ} \mathrm{C}\right)$ and humidity $(85 \%$ Relative Humidity), to be removed after five days. After demoulding, the upper face was trimmed (Figure 4a) and the specimen was completely wrapped in cling film (Figure $4 \mathrm{~b}$ ) before being stored back in the constant temperature and humidity room. Immediately before testing, at 28 days curing, the specimens were carefully measured and weighted. A $250 \mathrm{kN}$ capacity Shimadzu Autograph hydraulic testing machine was used with a $100 \mathrm{kN}$ load cell fitted, and every final result obtained was the average of 3 tested specimens.

Figure 3: Specimen preparation - visual texture of the GJG8 mixture

Figure 4: Specimen preparation: (a) demoulding after 48 hours; (b) wrapped in cling film

\subsection{Setting time}

The Vicat method was used to evaluate the setting time of the mixtures according with the proper European standard [14]. Each grout was poured in the mould, as shown in Figure 5, which was then set on the Vicat equipment (Figure 6) prior to the start of the test. 
Figure 6: Vicat equipment used

\subsection{Fluidity}

To analyse the fluidity of the grouts immediately after its fabrication, the cone method proposed in European standards [15] was used. The mentioned standard defines the geometry of the cone (Figure 7), which is very similar to the well-known Marsh funnel. The test consists of pouring a stated quantity of grout through the cone, when in vertical position, and determining the time of efflux of 1 litre. Room temperature at the time of the tests was $21^{\circ} \mathrm{C}$.

Figure 7: Standard flow cone [15]

\subsection{Capillary absorption}

According to [16], the cylindrical specimens used in this test needs to have $105 \mathrm{~mm}$ (diameter) by $25 \mathrm{~mm}$ (height). After the moulding process, which was performed using vibrocompaction, the specimens were covered in film while still inside the mould (Figure 8a) and cured for $24 \mathrm{~h}$ in standard laboratory climate of $20 \pm 2^{\circ} \mathrm{C}$ temperature and $60 \pm 5 \% \mathrm{RH}$. After that, they were unwrapped, demoulded (Figure 8b) and left to cure in the previous conditions for 26 days. The test consists of determining the water uptake into the specimen, at appropriate intervals, after being left on a shallow tray with a water level of approximately 2 mm. A total of 6 readings were taken (minimum number required), after $0,12,30,60,120$, 240 and 1440 minutes. Each reading consisted in determining the mass of the specimen after it was wiped with absorbent paper in order to remove surplus water. The water uptake per unit 
area $(i)$ is calculated as the ratio between the absorbed weight of water and the surface area of the test face [16]. Since the dependence between the water absorption and the square root of time is approximately linear, the water sorption coefficient $(S)$ is the gradient of the line representing $i$ as a function of the square root of the time of immersion $(h)$.

Figure 8: Specimen still in the mould and covered in film (a); Demoulding of the specimen (b)

\subsection{Shrinkage and expansion}

Shrinkage / expansion tests were performed according to Portuguese standards [17] to determine strain variations of the grouts in two different conditions. For the shrinkage analysis the curing was processed in a climatic chamber with $20 \pm 2{ }^{\circ} \mathrm{C}$ temperature and $60 \pm$ $5 \% \mathrm{RH}$, with the specimens wrapped in film and still inside the moulds for the first 48 hours. For the expansion analysis the specimens were cured also in a climatic chamber but with $20 \pm$ $2{ }^{\circ} \mathrm{C}$ temperature and $>95 \%$ RH. Prismatic specimens with 40 x 40 (base) x 160 (height) $\mathrm{mm}^{3}$ were moulded with the gauge studs already in place (Figure 9) and monitored over a period of 90 days, with measurements at 2, 5, 7, 9, 14, 21, 28, 60 and 90 days. Immediately after each specimen was demoulded, the first reading was taken and the value obtained was considered the reference for the remaining measurements (age "zero"). A length comparator (Figure 10) was used to measure strain variations. Each result presented is the average of the values obtained with two specimens. Mass variation with curing time was also measured for specimens cured in shrinkage and expansion conditions.

Figure 9: Specimens immediately after being demoulded showing the gauge studs 


\section{Results and discussion}

\subsection{Compressive strength}

Figure 11 shows the general collapse mode during the UCS tests on cubic specimens after 28 days curing. The fragile behavior of this material, which was a constant throughout these tests, is clear in this image. Table 4 indicates the UCS values together with the measured density of each specimen just before each test. It can be seen that the mixtures with an activator / ash ratio lower than 1 (GJG7, GJG8 and GJG10) achieved an average unit weight $6.1 \%$ higher than the average value obtained with mixtures GJG1, GJG2 and GJG4, which had an activator / ash ratio above 1. Regarding the strength results, it can be concluded that although mixtures GJG2 and GJG8 had the same sodium / ash ratio of mixtures GJG4 and GJG10, respectively, the lower sodium concentrations of GJG4 and GJG10 (which was obtained by increasing the water content used for mixtures GJG2 and GJG8), resulted in lower UCS values. Others authors have reached similar conclusions regarding the correlation between compressive strength and $\mathrm{Na} 2 \mathrm{O}$ concentration [18-20].

Figure 11: General view of the collapse mode during the UCS tests

Table 4: Unit weight and UCS results at 28 days curing 
Also of significance is the fact that the highest strength results were obtained for both sets of values (activator / ash ratio below and above 1), with the mixtures that possessed the highest unit weight (GJG2 and GJG8), suggesting that this parameter (unit weight) could be used to design these grouts due to the high correlation with the uniaxial strength.

Figure 12 represents the results of the UCS tests. The determination coefficient $\left(\mathrm{R}^{2}\right)$ of 0.902 obtained allows the conclusion that an increase in the activator / ash ratio results in a decrease in strength, which is probably due to the fact that the increase in this ratio was obtained by increasing the water content in the mixture, therefore decreasing the $\mathrm{Na}_{2} \mathrm{O}$ concentration.

Figure 12: UCS as a function of the activator / ash ratio

\subsection{Setting time}

This parameter was impossible to determine due to the very slow setting of the mixtures used, which is known to be significantly slower than the setting time of cement based grouts [4]. During the tests it was possible to conclude that the setting process is not homogenous, since the upper layer of the grout mass was hardening at a significant higher rate than the remaining volume. This was discovered when the Vicat needle was able to puncture the upper layer of the grout, exposing the fresh material underneath (Figure 13). The puncture would allow the upper harden layer to mix with the fresh grout, which would result in the loss of the already achieved hardness. Therefore, this test does not seem to be the most appropriate to evaluate this parameter in activated fly ash grouts. 


\subsection{Fluidity}

The results obtained using the cone method described in European standards [15] are presented in Table 5 and Figure 14. Based on the $\mathrm{R}^{2}$ values, it is possible to conclude that, as expected, the flow time is clearly controlled by the unit weight (Figure 14a) (an increase in this parameter represents a decrease in fluidity) and the liquid phase available (Figure 14b) (increasing the activator / ash ratio results in a decrease in flow time). Regarding the variation of time of flow as a function of the UCS (Figure 14c), it seems that an increase in both strength and fluidity is not possible, since an increase in fluidity can only be obtained by increasing the water content, which in turn reduces the alkali concentration in the mixture and consequently its mechanical strength. However, this can be overcome by correcting the grout composition, namely by increasing the total $\mathrm{Na}_{2} \mathrm{O}$, but that will change the $\mathrm{Na}_{2} \mathrm{O} /$ ash ratio, which according to previous results $[3,4]$, does have an optimum value. Also, the increase in alkali content represents an increase in the cost, and that needs also to be put in perspective. The fluidity / strength compromise is of significant importance and should be the object of further research.

Table 5: Fluidity results for an average room temperature of $21^{\circ} \mathrm{C}$

Figure 14: Flow time as a function of the unit weight (a); activator / ash ratio (b) and UCS (c)

\subsection{Capillary absorption}


Capillary action, a consequence of the contact between water and a porous material, can be seen as a measure of the pore dimensions of the material, since an increase in the former is the result of a decrease of the latter. This property of the material depends on the surface tension, viscosity and density of the water, on the angle of pore wall relatively to the water table and on the pore radius. It is usually described by the water sorption coefficient $S$. Also of significance is that the smaller the pores dimensions, the lower the speed of the water travelling inside the material. The GJG4 specimen was destroyed after curing and therefore no results are presented for this mixture. Results on the remaining mixtures are presented in Figure 15, which shows that the entire sorption happened almost immediately. Since the absorption did not give a straight line, the value of $S$ was calculated as suggested in [16], i.e. using the last value measured. Results obtained (Table 6) indicate that the sorption of this material is in general relatively low when compared with results from similar tests on concrete specimens. Bertolini et al [21] reported that the $S$ values for concrete are usually between $2 \mathrm{~kg} /\left(\mathrm{m}^{2} \mathrm{~h}^{0.5}\right)$ - for normal strength concrete, and $6 \mathrm{~kg} /\left(\mathrm{m}^{2} \mathrm{~h}^{0.5}\right)$ - for high-strength concrete, while the average $S$ value obtained in these tests was $1.39 \mathrm{~kg} /\left(\mathrm{m}^{2} \mathrm{~h}^{0.5}\right)$ (Table 6). Overall, results from this test allow the conclusion that the activator / ash grout is not very porous, due to the relatively low $S$ values obtained. This might be explained by the spherical shape and small size of the fly ash particles, which increase grout density relatively to cement or lime based grouts and therefore minimizes material voids [22]. Another possible conclusion is that almost all the absorption happens immediately after the mixture is in contact with the water. However, it has been reported [23] that, although the sorption rate decreases very significantly after short periods (few hours), it is still active on the long term, due to the fact that larger pores control capillary suction at early stages and smaller pores control it afterwards. 


\subsection{Shrinkage and expansion}

The test data are plotted in Figure 16 and Figure 17. Specimens GJG7 and GJG8 used for the expansion analysis were damaged while being handled and the results were therefore discarded. In general, the shrinkage values were similar to those usually reported for concrete [24,25] and mortar [26], for similar curing conditions. However, values obtained with mixtures GJG4 and GJG8 were significantly higher than the remaining values and higher than average values reported in the literature, for concrete, by a factor between 3 and 5 . A possible reason for the relative behavior of the mixtures in pairs (GJG4/GJG8, GJG1/GJG2 and GJG7/GJG10) is hard to detect, since there is no common factor to the two mixtures of each pair $\left(\mathrm{Na}_{2} \mathrm{O} /\right.$ ash and activator / ash ratios, and $\mathrm{NaOH}$ concentration). The beneficial effect of fly ash on the drying shrinkage of concrete was previously reported [26]. Therefore, it is somehow surprising that these ash-based grouts have shown a relatively higher shrinkage over time. However, Wallah \& Rangan [27] performed shrinkage tests on fly ash - based geopolymer specimens cured at $60^{\circ} \mathrm{C}$ and at ambient temperature, reporting significantly lower shrinkage values for the heat cured ones (around $0.1 \mathrm{~mm} / \mathrm{m}$ ) and similar values $(1.5$ $\mathrm{mm} / \mathrm{m}$ ) for the specimens cured at ambient temperature. Chi [19] also reported higher shrinkage values with alkali activated slag concrete than with Portland cement concrete. Most of the shrinkage happens in the first 28 days, with only marginal variations between 28 and 90 days curing, which is also in accordance with the results reported by Wallah \& Rangan [27]. Mass variation during the shrinkage analysis was as expected, i.e. the curing process allowed the loss of constitutive water, which resulted in mass reduction. 
Regarding the expansion results, the relative behavior reported for the shrinkage analysis was again observed, since mixture GJG4 showed higher expansion than mixture GJG2, which in turn showed higher expansion than mixture GJG10. However, in this case the results from mixtures GJG7 and GJG8 are not available, and the results from mixture GJG1 are available only for the first three readings (but they are again, as in the shrinkage analysis, very close to GJG2). As expected, an increase in mass was observed due to the high degree of saturation of the curing ambient. However, while the drying curing revealed a similar mass loss for all the mixtures, in this case mixture GJG4 (which showed the larger strain), recorded a significantly lower mass variation than the remaining mixtures.

Figure 16: Results from the shrinkage analysis [Strain (a); Mass variation (b)]

Figure 17: Results from the expansion analysis: (a) Strain; (b) Mass variation

\subsection{XRD Analysis}

Figure 18 shows the X-ray diffractograms of the original fly ash and the GJG8 mixture after 28 days curing. The characteristic hump that usually reveals the presence of glass content in fly ash and metakaolin [28,29] can be seen on the fly ash between $20^{\circ}$ and $35^{\circ} 2 \theta$, revealing its reactive potential. The mentioned hump shifts to the right after alkaline activation, between $25^{\circ}$ and $40^{\circ} 2 \theta$, while also decreasing in intensity. These reactions are expected to form crystalline phases $[18,28]$, which was confirmed in the current analysis by comparing both diffractograms. 


\section{Conclusions}

The properties of the injection grout assessed, when in its fresh state, control the behaviour of the soil-grout mix after the hardening process takes place. It is essential that grouts injected in a porous media are capable of filling the voids in order to form a higher strength structural matrix. This study aimed at understanding the rheology of an alkaline activated fly ash based grout to be used in jet grouting. It was shown that a very significant correlation exists between fluidity and UCS and between density and UCS. The apparent influence of the unit weight on mechanical strength means that the grout composition has to be decided with care, because the strength is favored by an increase in density (which implies an increase in viscosity and cohesion of the grout), while the grouted volume and the flow rate are increased by a decrease in the unit weight. To improve fluidity without compromising strength, it is necessary to increase the alkali / ash ratio of the grout, in order to maintain $\mathrm{Na}_{2} \mathrm{O}$ concentration. This apparent cost increase might be mitigated by the fact that a more effective grout, in terms of both rheology and strength, is capable of delivering jet grouting columns that use less grout volumes to achieve a satisfactory structural behaviour. On the other hand, even the lower strength value obtained, corresponding to the best fluidity result, is acceptable for a jet grouting application, which suggests that the design of the grout could be based almost entirely on the rheological properties. Regarding shrinkage and expansion during the curing process, general previous results were confirmed, in the sense that alkaline activated binders are more sensitive to curing conditions, namely humidity, than cement grouts. The porosity 
seems to be lower than cement grouts, which is an advantage in terms of durability in such harsh conditions as those that can be expected in a soil media.

\section{Acknowledgments}

The authors wish to acknowledge the contribution of Teixeira Duarte Engenharia e Construções S.A. company with the funding for this research project, Dra. Lisete Fernandes with the microstructural analysis (SEM, EDS, XRD) and PEGOP - Energia Eléctrica, S.A. company for the kind supply of the fly ash used.

\section{References}

[1] Escalante-Garcia JI, Espinoza-Perez LJ, Gorokhovsky a., Gomez-Zamorano LY. Coarse blast furnace slag as a cementitious material, comparative study as a partial replacement of Portland cement and as an alkali activated cement. Construction and Building Materials 2009;23:2511-7.

[2] Tomlinson MJ. Foundation Design and Construction. Pearson Ed. Harlow: Prentice Hall; 2001.

[3] Cristelo N, Glendinning S, Teixeira Pinto A. Deep soft soil improvement by alkaline activation. Proceedings of the ICE - Ground Improvement 2011;164:73-82.

[4] Cristelo N, Glendinning S, Fernandes L, Teixeira Pinto A. Effects of alkaline-activated fly ash and Portland cement on soft soil stabilisation. Acta Geotechnica 2013.

[5] Romagnoli M, Leonelli C, Kamse E, Lassinantti Gualtieri M. Rheology of geopolymer by DOE approach. Construction and Building Materials 2012;36:251-8.

[6] Essler R, Yoshida H. Jet grouting. In: Moseley MP, Kirsch K, editors. Ground Improvement, 2nd edition, Spon Press; 2004. 160-96.

[7] Croce P, Flora A. Analysis of Single-Fluid Jet Grouting. In: Raison CA, editor. Ground And Soil Improvement, Thomas Telford; 2004, 177-86. 
[8] Lunardi P. Ground improvement by means of jet-grouting. Proceedings of the ICE Ground Improvement 1997;2:65-85.

[9] Hardjito D, Rangan B V. Development and properties of low-calcium fly ash-based geopolymer concrete - Research Report GC 1. Perth: 2005.

[10] Criado M, Fernández-Jiménez a., De la Torre a. G, Aranda M a. G, Palomo a. An XRD study of the effect of the $\mathrm{SiO} 2 / \mathrm{Na} 2 \mathrm{O}$ ratio on the alkali activation of fly ash. Cement and Concrete Research 2007;37:671-9.

[11] Villa C, Pecina ET, Torres R, Gómez L. Geopolymer synthesis using alkaline activation of natural zeolite. Construction and Building Materials 2010;24:2084-90.

[12] Criado M, Fernández-Jiménez a., De la Torre a. G, Aranda M a. G, Palomo a. An XRD study of the effect of the $\mathrm{SiO} 2 / \mathrm{Na} 2 \mathrm{O}$ ratio on the alkali activation of fly ash. Cement and Concrete Research 2007;37:671-9.

[13] Winnefeld F, Leemann A, Lucuk M, Svoboda P, Neuroth M. Assessment of phase formation in alkali activated low and high calcium fly ashes in building materials. Construction and Building Materials 2010;24:1086-93.

[14] BSi EN 196-3. BS EN 196-3: 2005 - Methods of testing cement. Determination of setting times and soundness. British Standards Institution, London.

[15] BSi EN 445. BS EN 445: 2007 Grout for prestressing tendons. Test methods. British Standards Institution, London.

[16] BSi EN 13057. BS EN 13057: 2002 - Products and systems for the protection and repair of concrete structures. Test methods. Determination of resistance of capillary absorption. British Standards Institution, London.

[17] Laboratório Nacional de Engenharia Civil. E 398 Betões. Determinação da retracção e da expansão 1993.

[18] Hu M, Zhu X, Long F. Alkali-activated fly ash-based geopolymers with zeolite or bentonite as additives. Cement and Concrete Composites 2009;31:762-8.

[19] Chi M. Effects of dosage of alkali-activated solution and curing conditions on the properties and durability of alkali-activated slag concrete. Construction and Building Materials 2012;35:240-5.

[20] Rashad AM, Zeedan SR. The effect of activator concentration on the residual strength of alkali-activated fly ash pastes subjected to thermal load. Construction and Building Materials 2011;25:3098-107.

[21] Bertolini L, Eisener B, Pedeferri P, Polder R. Corrosion of Steel in Concrete. Morlenbach: Wiley-VCH; 2004.

[22] Bras A, Henriques FMA, Cidade MT. Effect of environmental temperature and fly ash addition in hydraulic lime grout behaviour. Construction and Building Materials 2010;24:1511-7. 
[23] Martys N, Ferraris C. Capillary transport in mortars and concrete. Cement and Concrete Research 1997;27:747-60.

[24] Le TT, Austin SA, Lim S, Buswell RA, Law R, Gibb AGF, et al. Hardened properties of high-performance printing concrete. Cement and Concrete Research 2012;42:55866.

[25] Bissonnette B, Pierre P, Pigeon M. Influence of key parameters on drying shrinkage of cementitious materials. Cement and Concrete Research 1999;29:1655-62.

[26] Atiş CD, Kiliç A, Sevim UK. Strength and shrinkage properties of mortar containing a nonstandard high-calcium fly ash. Cement and Concrete Research 2004;34:99-102.

[27] Wallah S, Rangan B. Low-calcium fly ash-based geopolymer concrete: Long-term properties. Perth, Curtin University of Technology 2006.

[28] Fernández-Jiménez A, Monzó M, Vicent M, Barba A, Palomo A. Alkaline activation of metakaolin-fly ash mixtures: Obtain of Zeoceramics and Zeocements. Microporous and Mesoporous Materials 2008;108:41-9.

[29] Ward C, French D. Characteristics of australian fly ashes - Technical Note 21. Pullenvale: 2003. 
Table 1: Statistical data regarding the fly ash particle's diameter

\begin{tabular}{lllllll}
\hline Points & $\begin{array}{l}\text { Max diam } \\
(\mu \mathrm{m})\end{array}$ & $\begin{array}{l}\text { Min diam } \\
(\mu \mathrm{m})\end{array}$ & $\begin{array}{l}\text { Mean } \\
(\mu \mathrm{m})\end{array}$ & $\begin{array}{l}\text { Std. dev. } \\
(\mu \mathrm{m})\end{array}$ & $\begin{array}{l}\text { Mode } \\
(\mu \mathrm{m})\end{array}$ & $\begin{array}{l}\text { Median } \\
(\mu \mathrm{m})\end{array}$ \\
\hline 126 & 44.51 & 3.72 & 11.64 & 8.05 & 9.10 & 8.90 \\
\hline
\end{tabular}


Table 2

Table 1: Chemical composition of the fly ash

\begin{tabular}{lllllllllll}
\hline Element & $\mathrm{Si}$ & $\mathrm{Al}$ & $\mathrm{Fe}$ & $\mathrm{Ca}$ & $\mathrm{K}$ & $\mathrm{Ti}$ & $\mathrm{Mg}$ & $\mathrm{Na}$ & $\mathrm{S}$ & $\mathrm{P}$ \\
\hline$(\%)$ & 48.81 & 21.77 & 14.74 & 3.85 & 4.42 & 1.79 & 1.56 & 1.31 & 1.17 & 0.58 \\
\hline
\end{tabular}


Table 1: Characterisation of the mixtures analysed

\begin{tabular}{llll}
\hline Ref & $\mathrm{Na}_{2} \mathrm{O} /$ Ash & $\begin{array}{l}\text { Activator } / \\
\text { Ash }\end{array}$ & $\begin{array}{l}\mathrm{NaOH} \\
\text { concentration } \\
\text { (molal) }\end{array}$ \\
\hline GJG1 & 0.250 & 1.33 & 12.5 \\
GJG2 & 0.230 & 1.22 & 12.5 \\
GJG4 & 0.230 & 1.39 & 10.0 \\
GJG7 & 0.170 & 0.92 & 12.5 \\
GJG8 & 0.155 & 0.82 & 12.5 \\
GJG10 & 0.155 & 0.94 & 10.0 \\
\hline
\end{tabular}


Table 1: Unit weight and UCS results at 28 days curing

\begin{tabular}{llllll}
\hline Ref & $\begin{array}{l}\text { Activator / } \\
\text { Ash }\end{array}$ & $\begin{array}{l}\text { Unit weight } \\
\left(\mathrm{kN} / \mathrm{m}^{3}\right)\end{array}$ & $\begin{array}{l}\text { USC } \\
(\mathrm{MPa})\end{array}$ & \\
\hline GJG1 & 1.33 & 16.31 & Mean & 2.1 & Mean \\
GJG2 & 1.22 & 16.81 & value: & 3.3 & value: \\
GJG4 & 1.39 & 15.73 & 16.28 & 1.9 & 2.4 \\
\hline GJG7 & 0.92 & 17.23 & Mean & 6.4 & Mean \\
GJG8 & 0.82 & 17.63 & value: & 8.5 & value: \\
GJG10 & 0.94 & 16.99 & 17.28 & 4.1 & 6.3 \\
\hline
\end{tabular}


Table 1: Fluidity results for an average room temperature of $21^{\circ} \mathrm{C}$

\begin{tabular}{llll}
\hline Ref & $\begin{array}{l}\text { Activator / } \\
\text { Ash }\end{array}$ & $\begin{array}{l}\text { Unit weight } \\
\left(\mathrm{kN} / \mathrm{m}^{3}\right)\end{array}$ & $\begin{array}{l}\text { Time } \\
(\mathrm{s})\end{array}$ \\
\hline GJG1 & 1.33 & 16.31 & 17.5 \\
GJG2 & 1.22 & 16.81 & 20.0 \\
GJG4 & 1.39 & 15.73 & 16.0 \\
\hline GJG7 & 0.92 & 17.23 & 23.0 \\
GJG8 & 0.82 & 17.63 & 26.0 \\
GJG10 & 0.94 & 16.99 & 24.0 \\
\hline
\end{tabular}


Table 1: Sorption coefficient values

\begin{tabular}{llll}
\hline Ref & $\begin{array}{l}\text { Sorption } \\
\text { coefficient } S \\
\left(\mathrm{~kg} /\left(\mathrm{m}^{2} \mathrm{~h}^{0.5}\right)\right)\end{array}$ & $\begin{array}{l}\text { Partial } \\
\text { average } S \\
\left(\mathrm{~kg} /\left(\mathrm{m}^{2} \mathrm{~h}^{0.5}\right)\right)\end{array}$ & $\begin{array}{l}\text { Total } \\
\text { average } S \\
\left(\mathrm{~kg} /\left(\mathrm{m}^{2} \mathrm{~h}^{0.5}\right)\right)\end{array}$ \\
\hline GJG1 & 1.29 & & \\
GJG2 & 1.45 & 1.37 & 1.39 \\
GJG4 & - & & \\
\hline GJG7 & 1.30 & \multirow{2}{*}{1.41} & \\
GJG8 & 1.48 & & \\
GJG10 & 1.45 & & \\
\hline
\end{tabular}




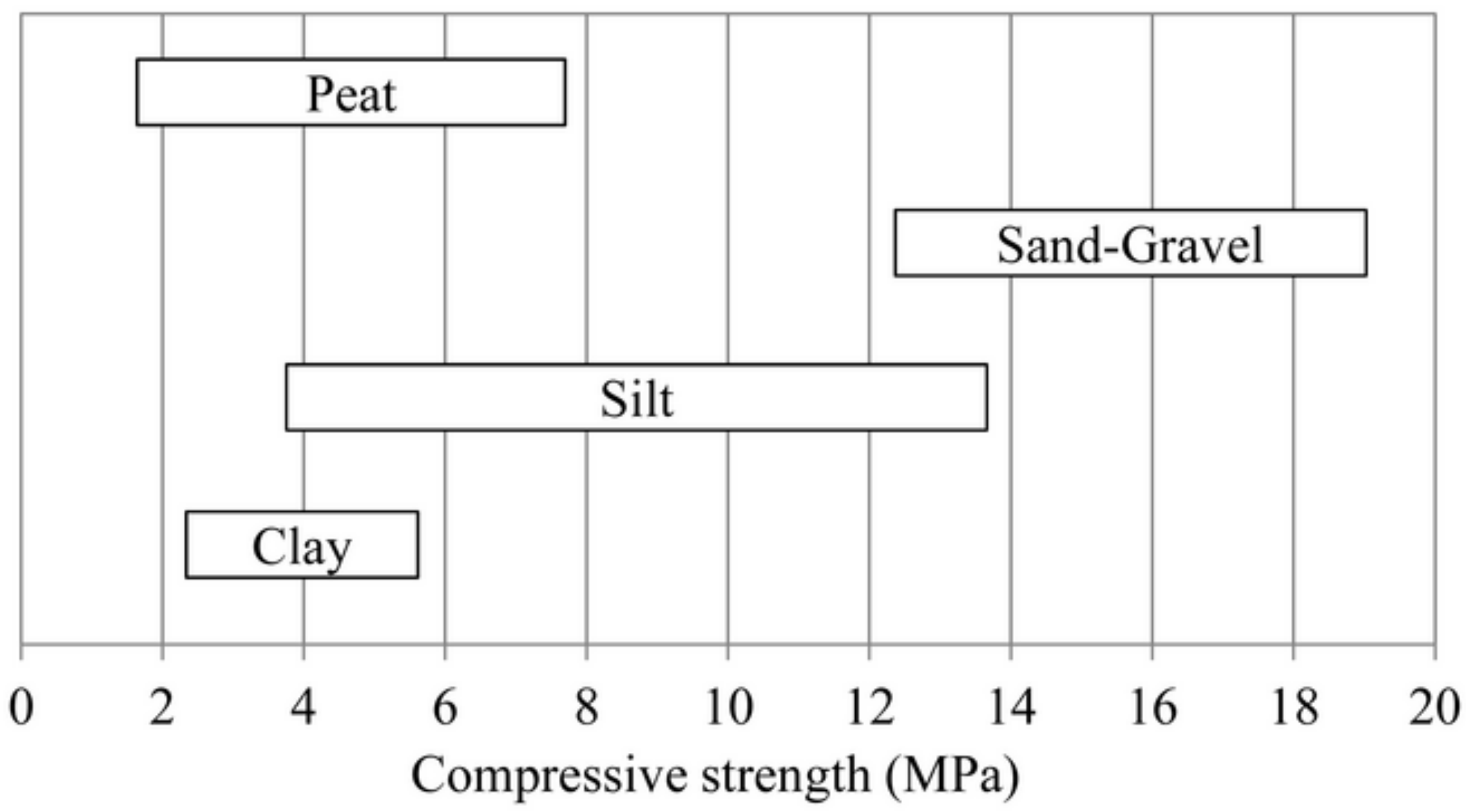


Click here to download high resolution image

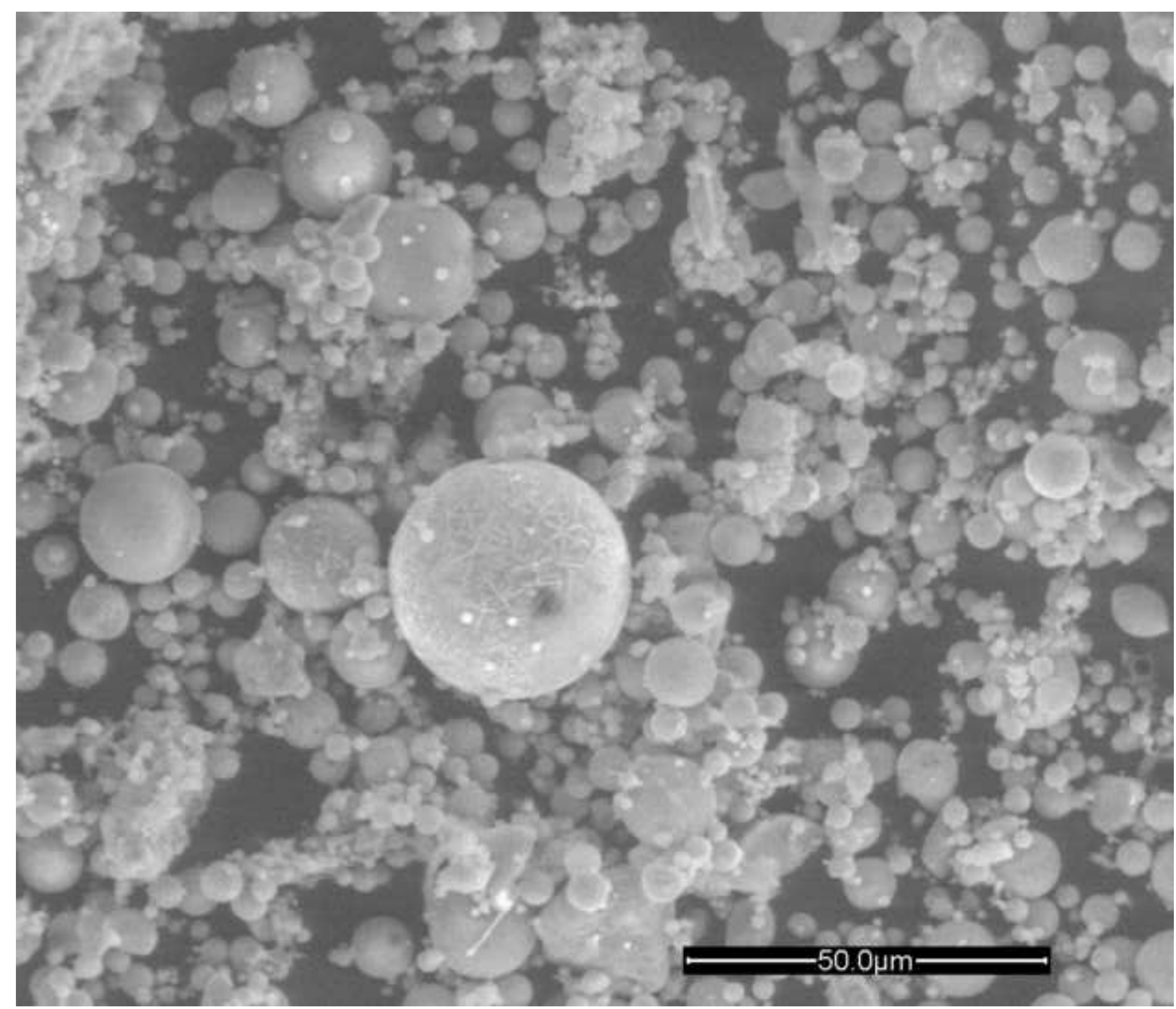


Click here to download high resolution image

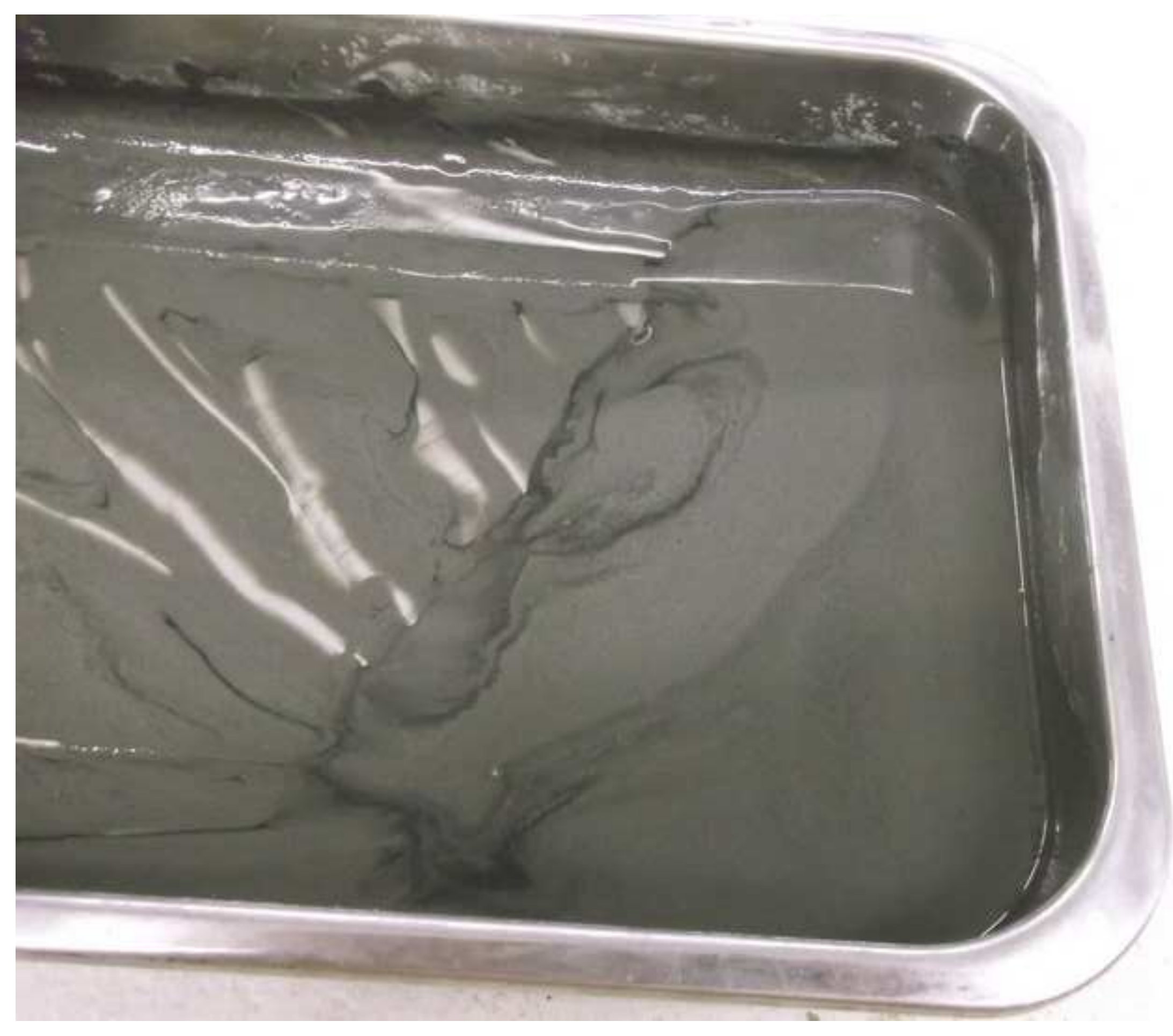


Figure $4 a$
Click here to download high resolution image

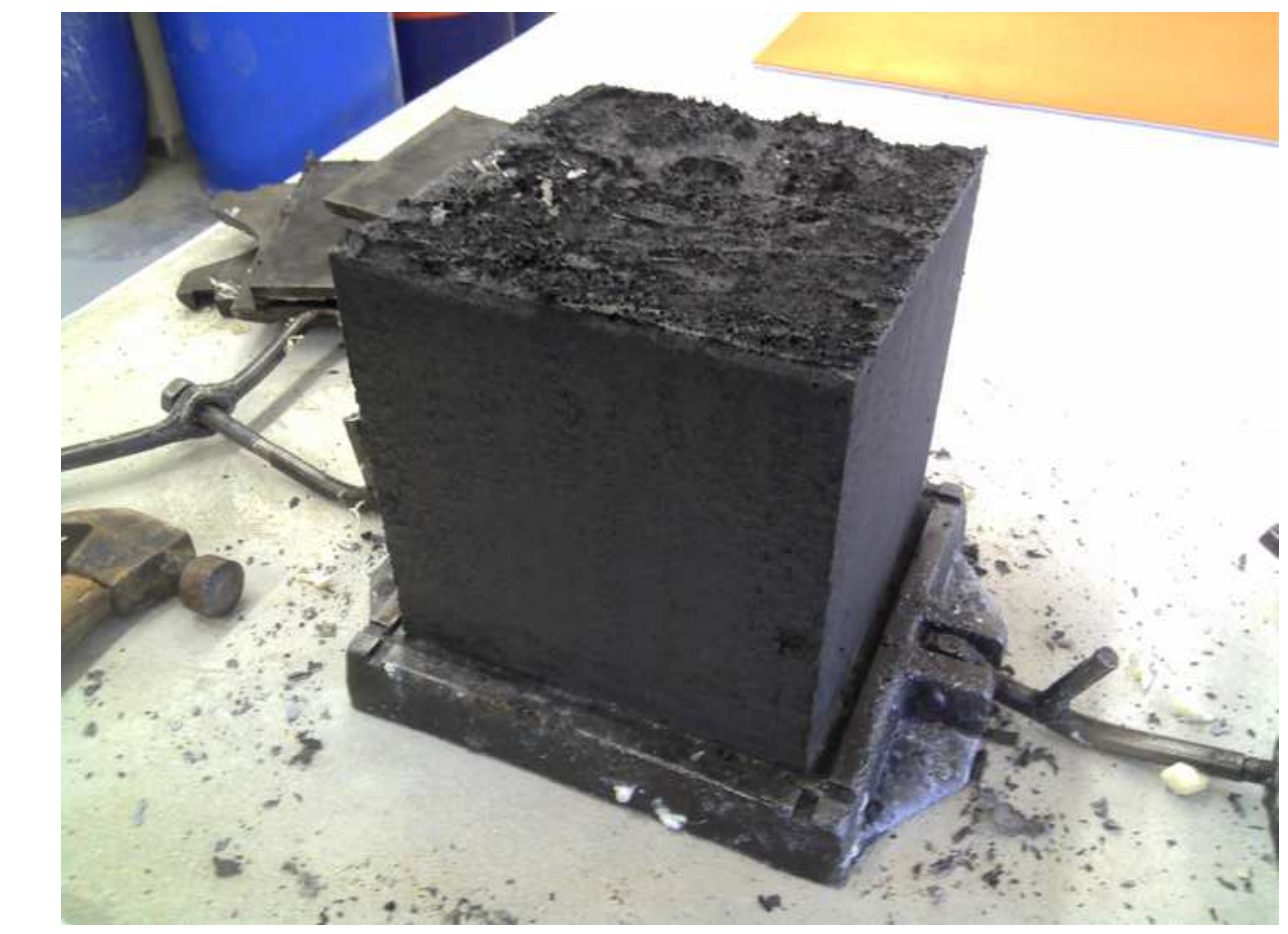




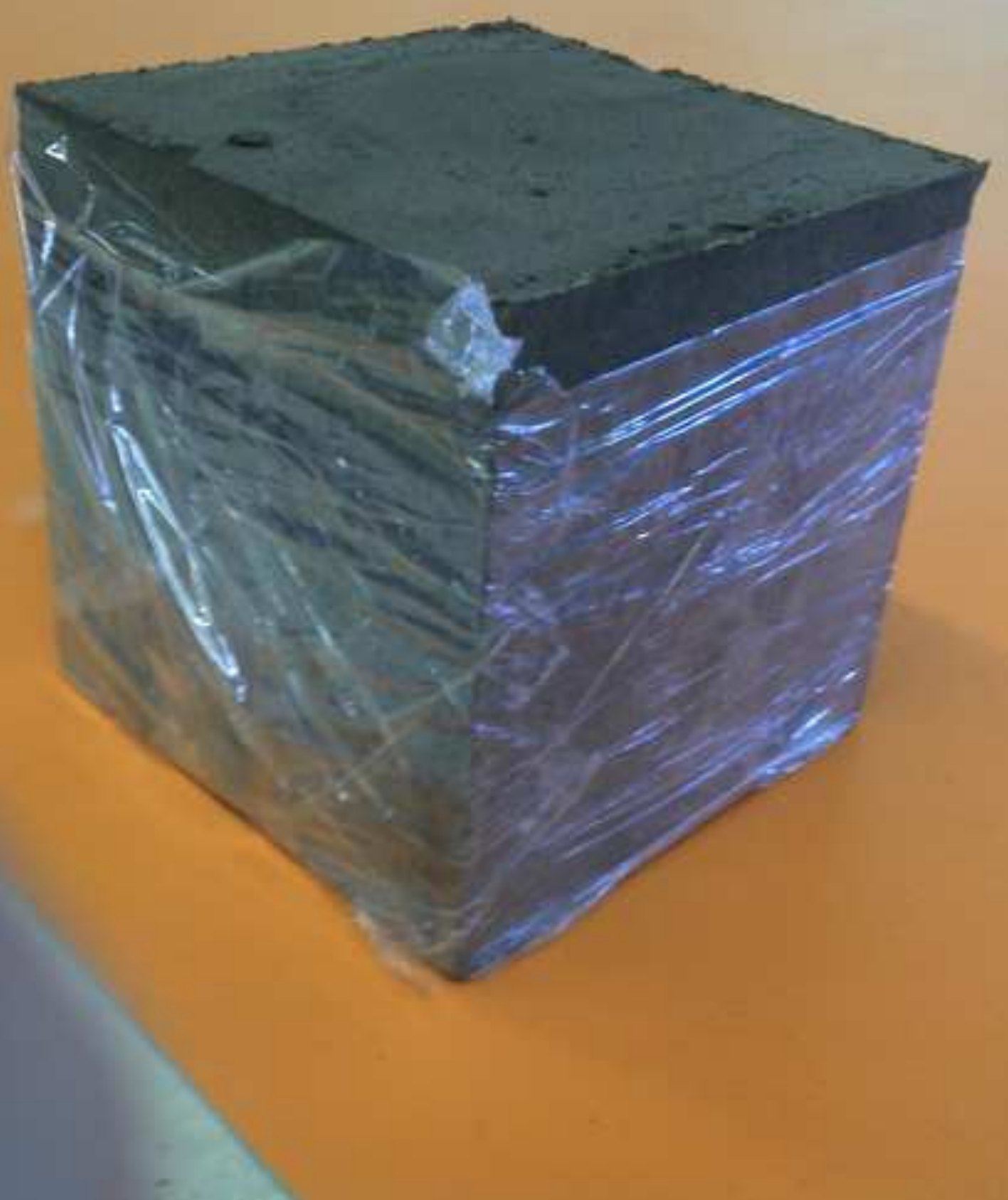




\section{Figure 5}

Click here to download high resolution image

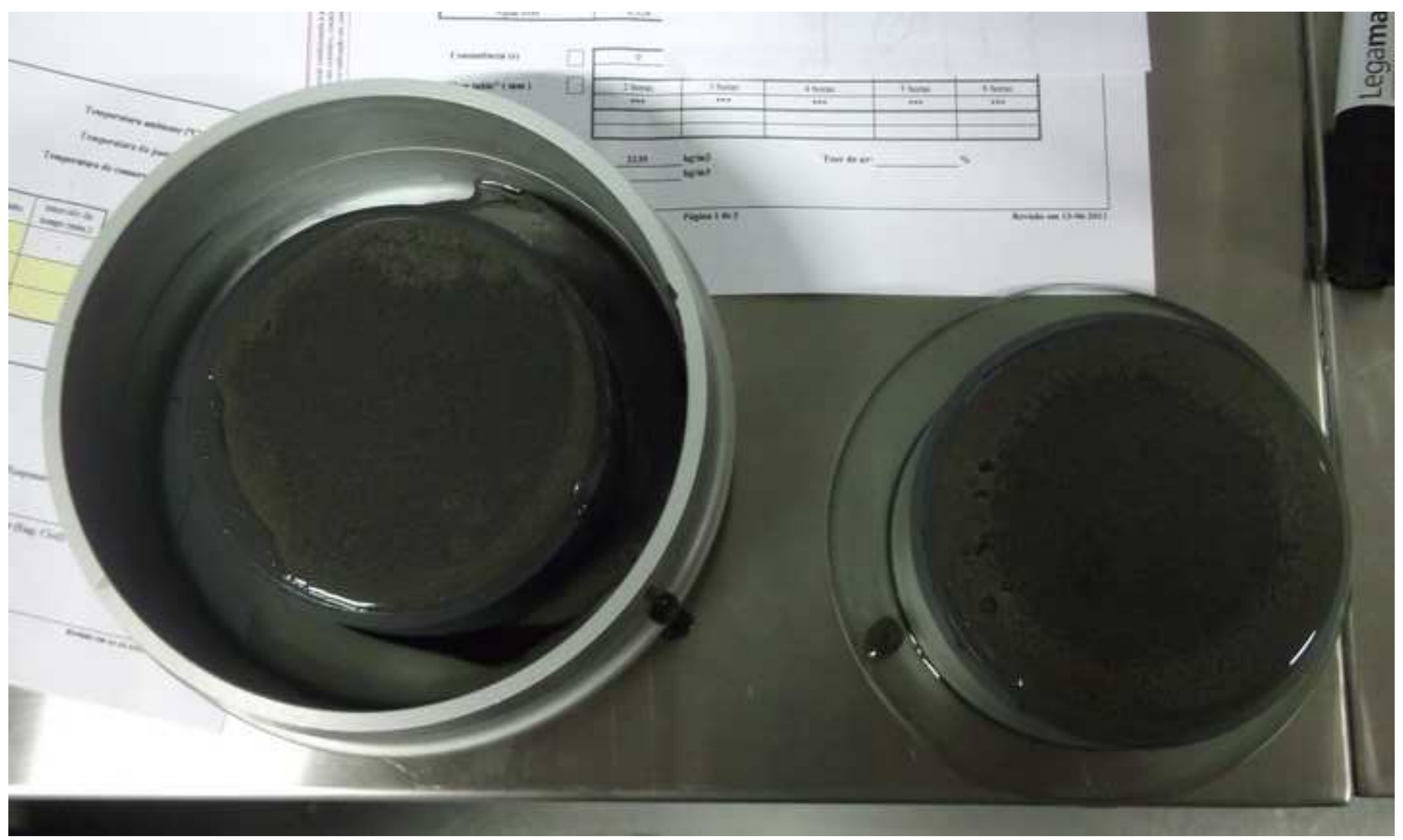


Click here to download high resolution image

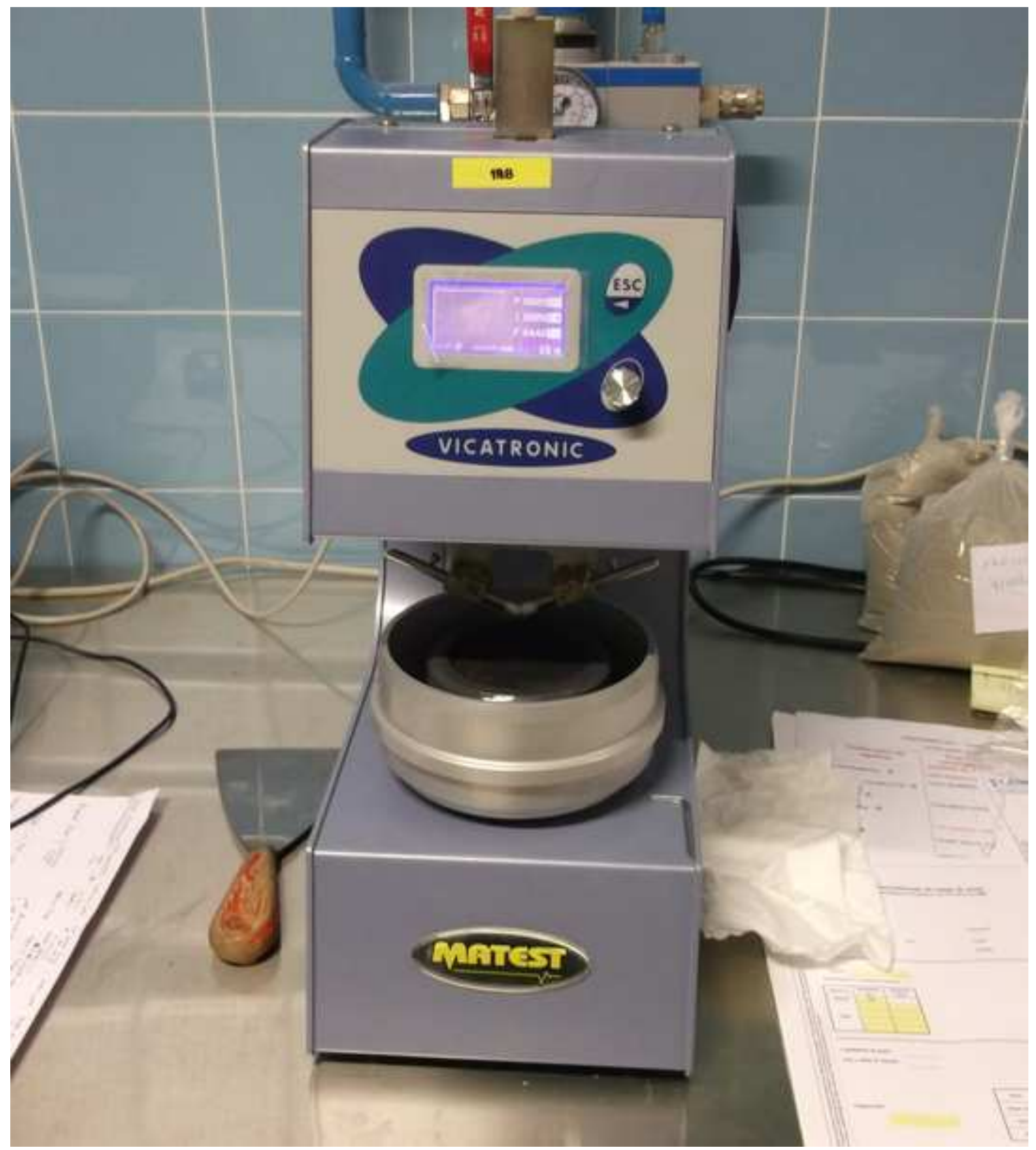


Click here to download high resolution image

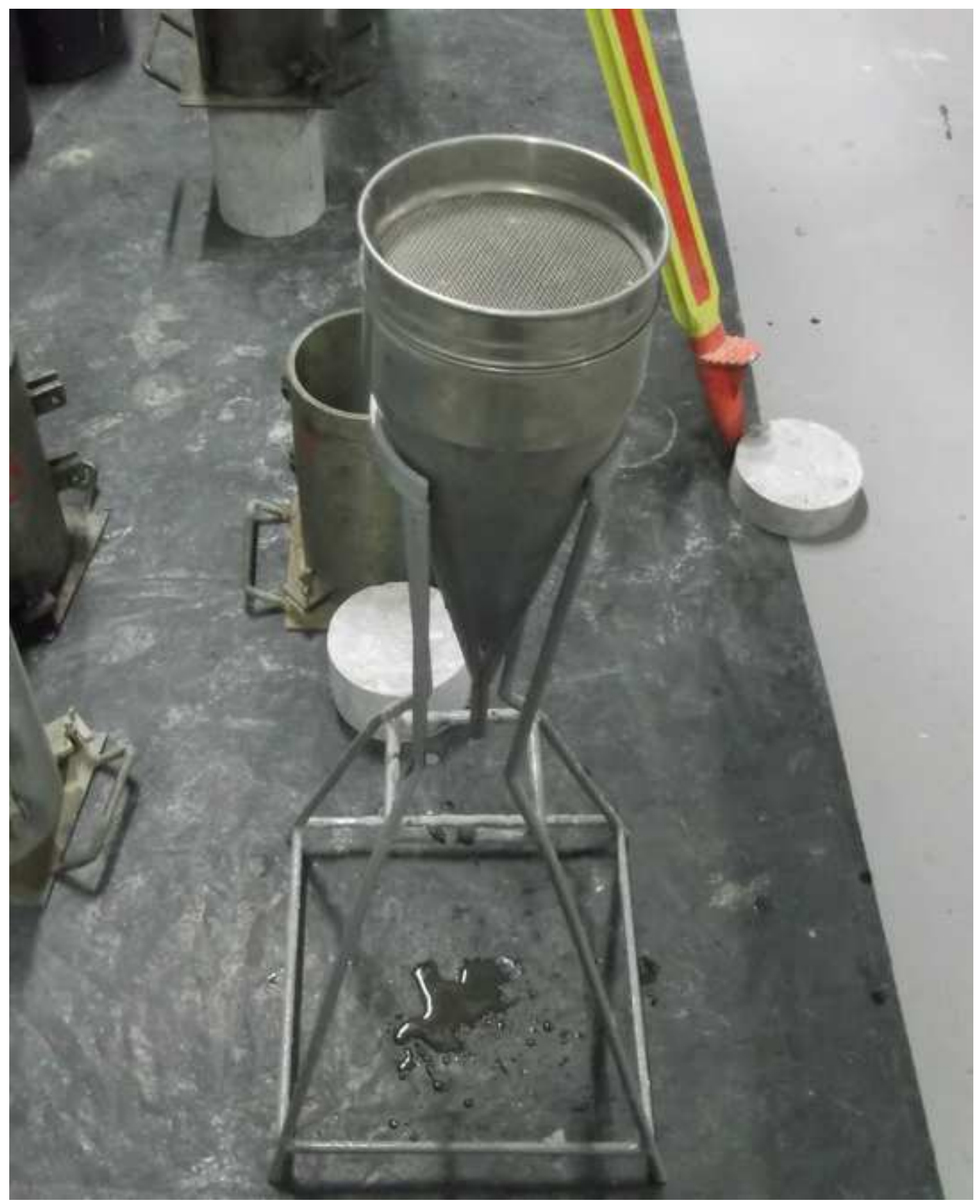


Click here to download high resolution image

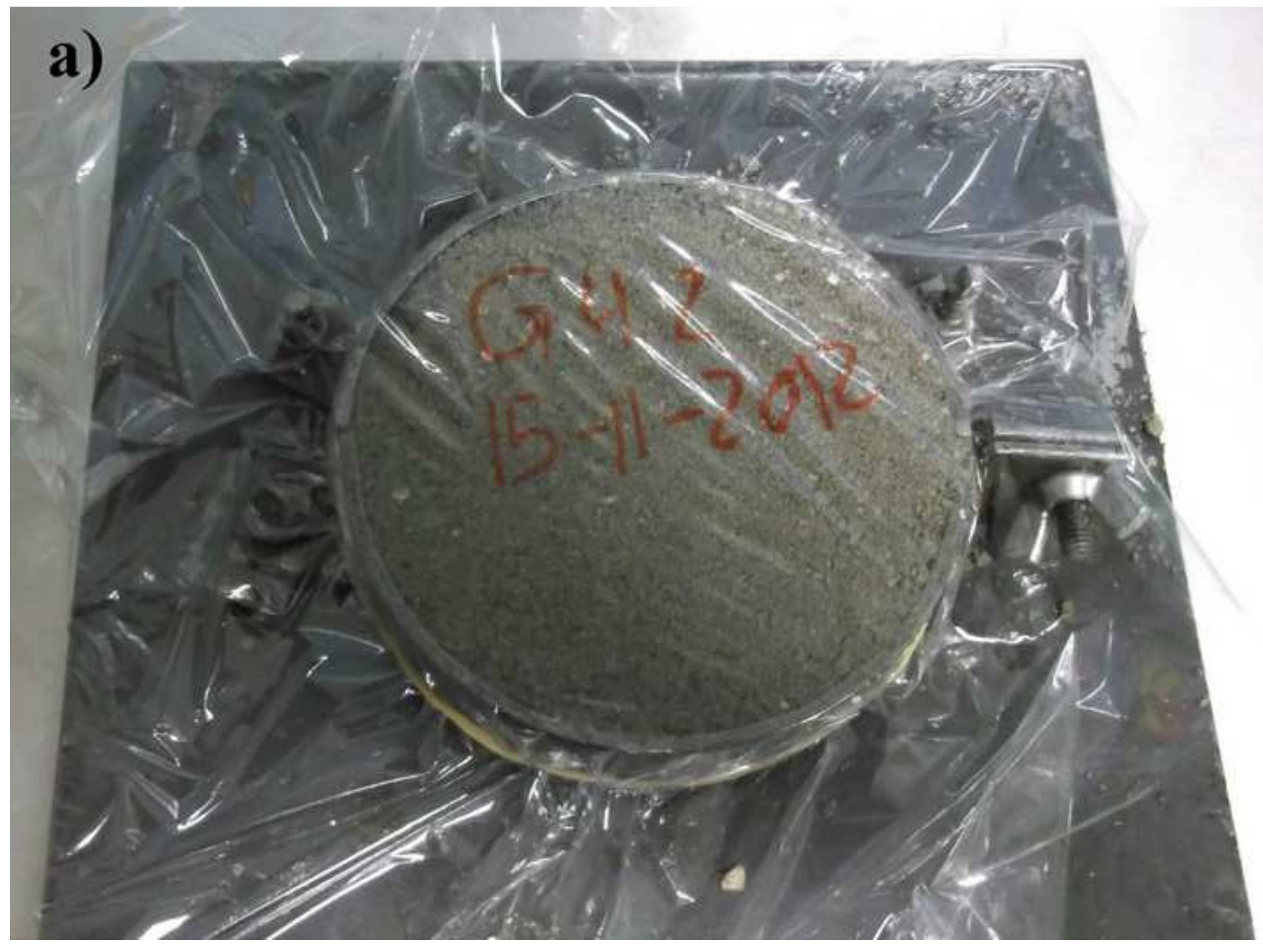


Click here to download high resolution image

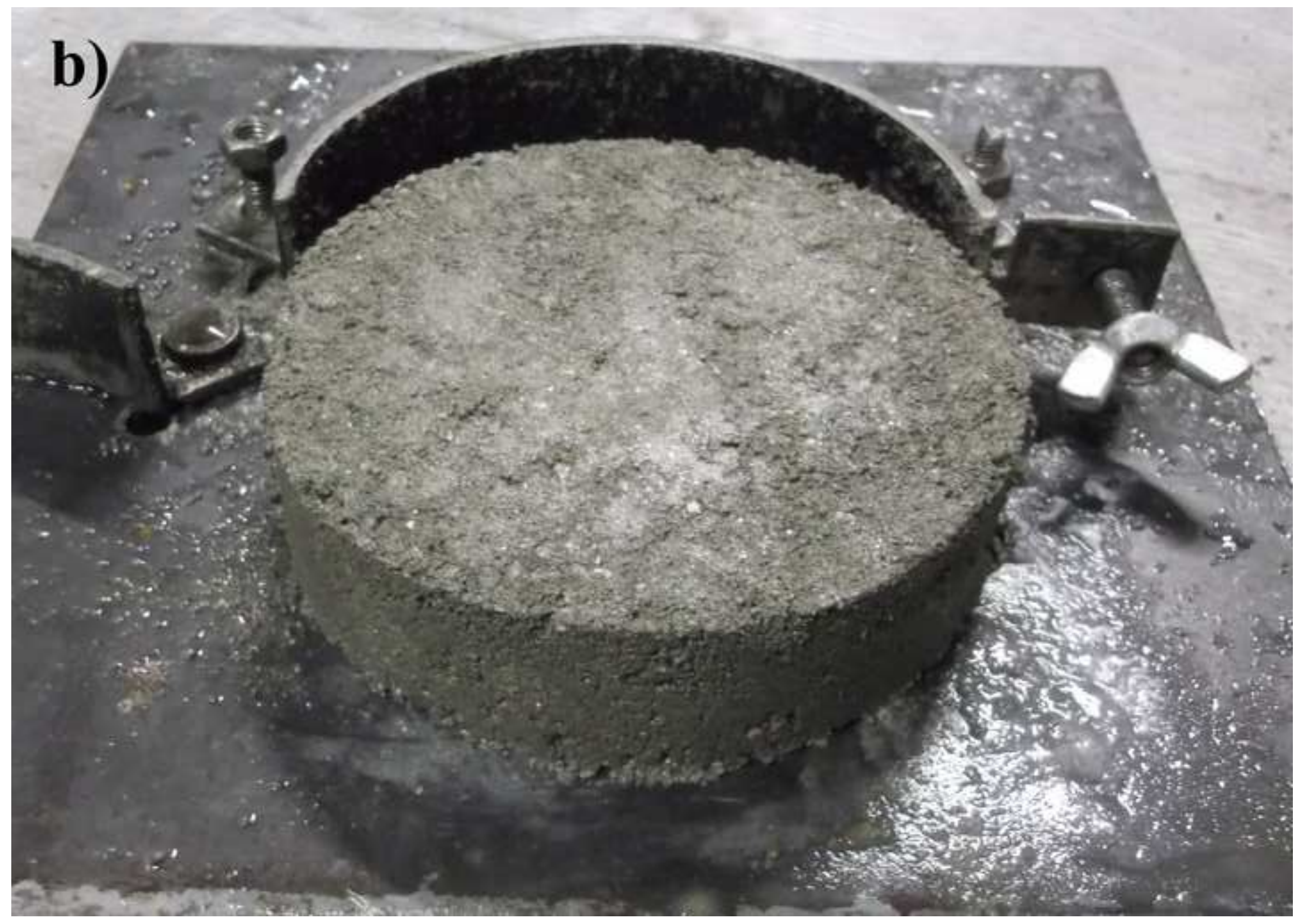


Click here to download high resolution image
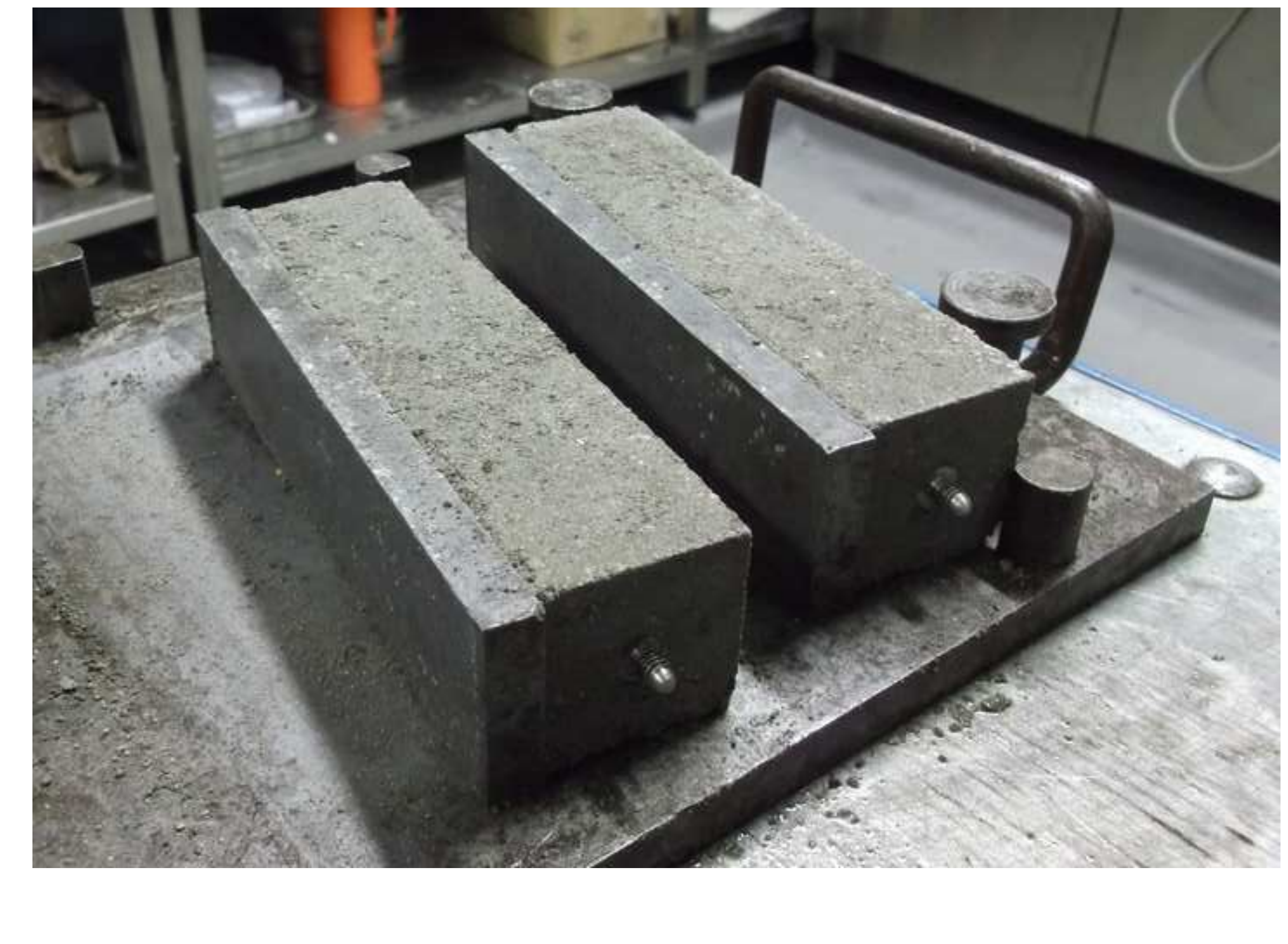

.

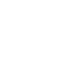

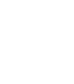


Click here to download high resolution image

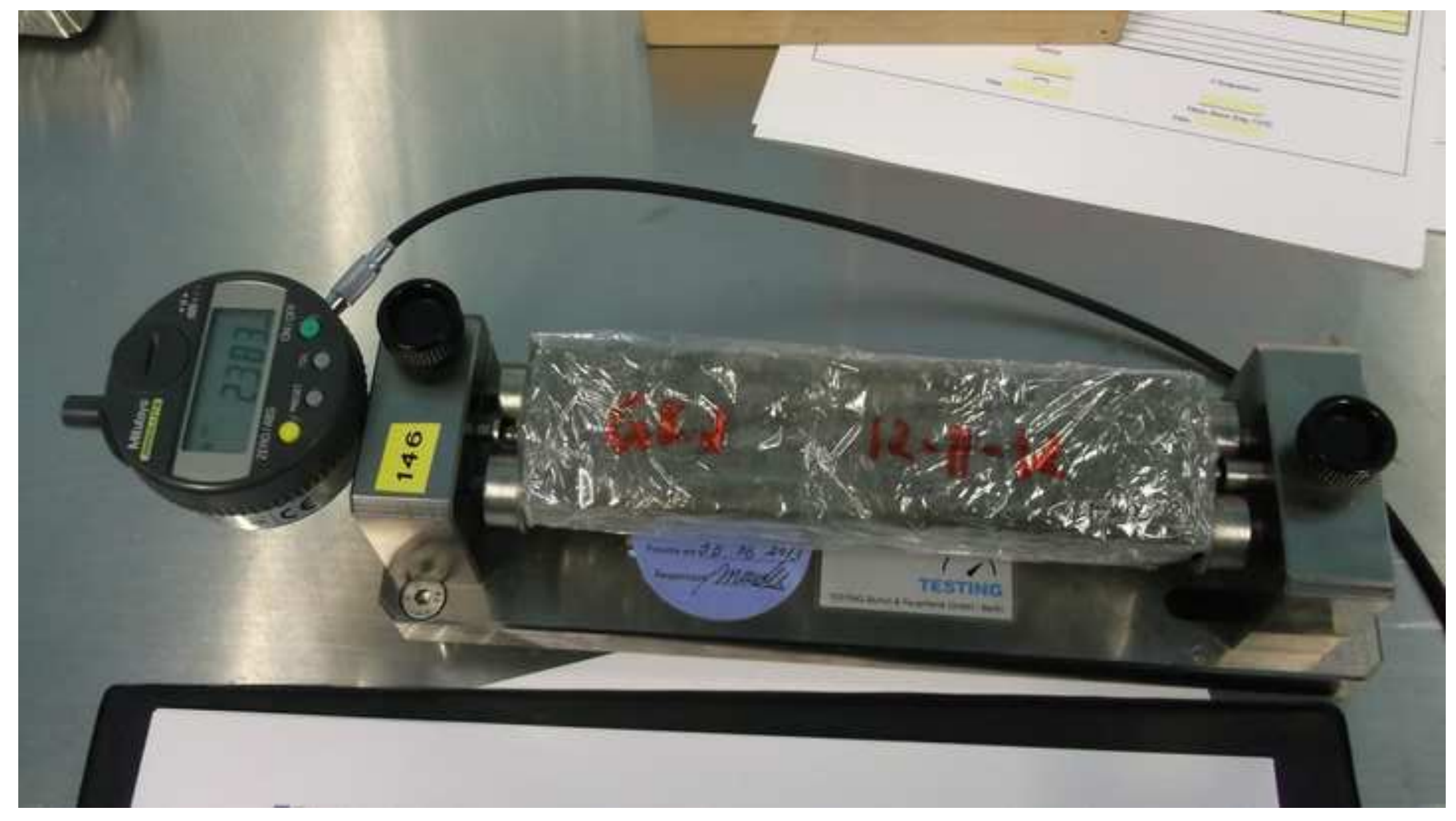

Click here to download high resolution image 
Figure 11
Click here to download high resolution image

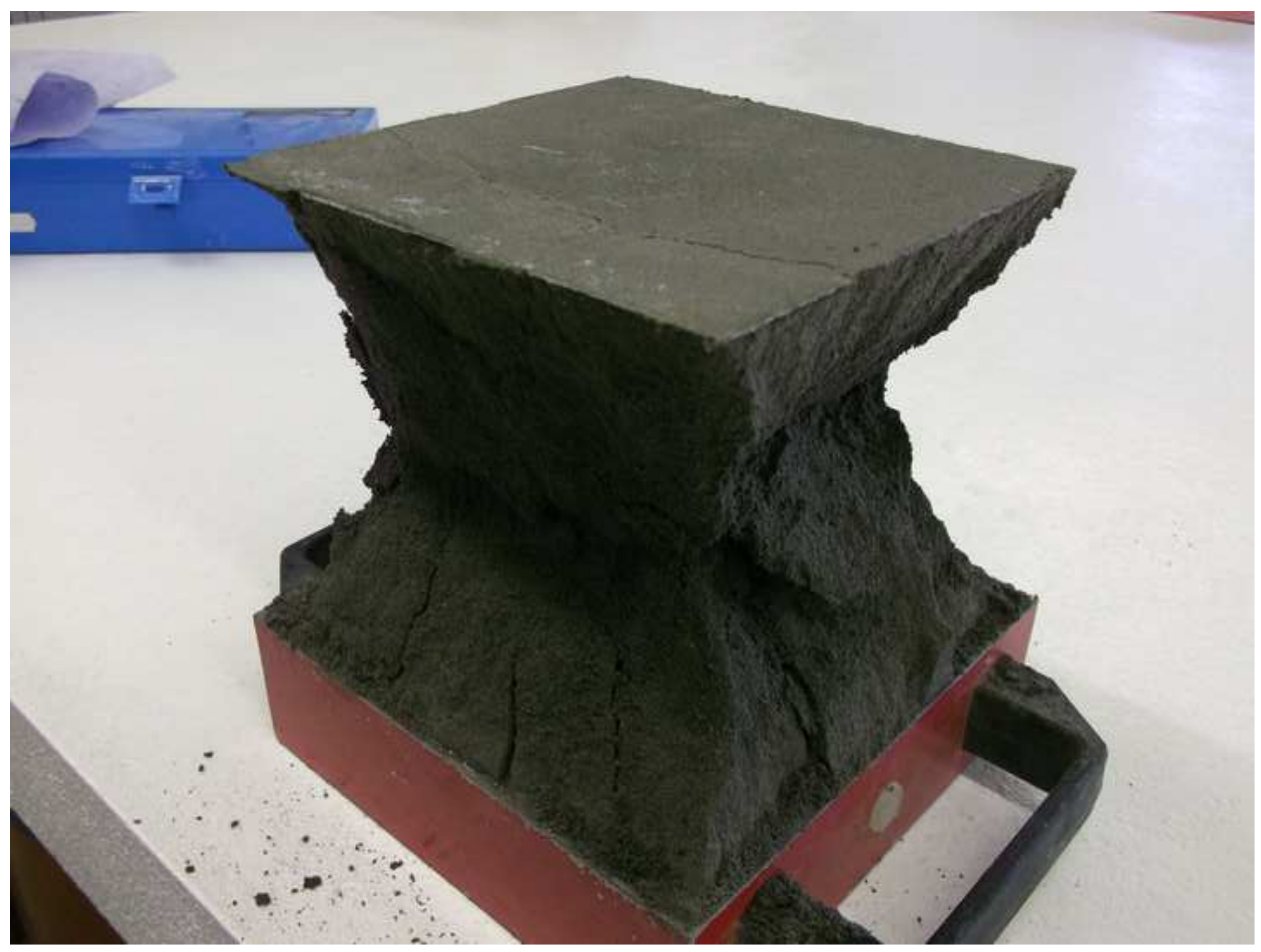


Figure 12
Click here to download high resolution image

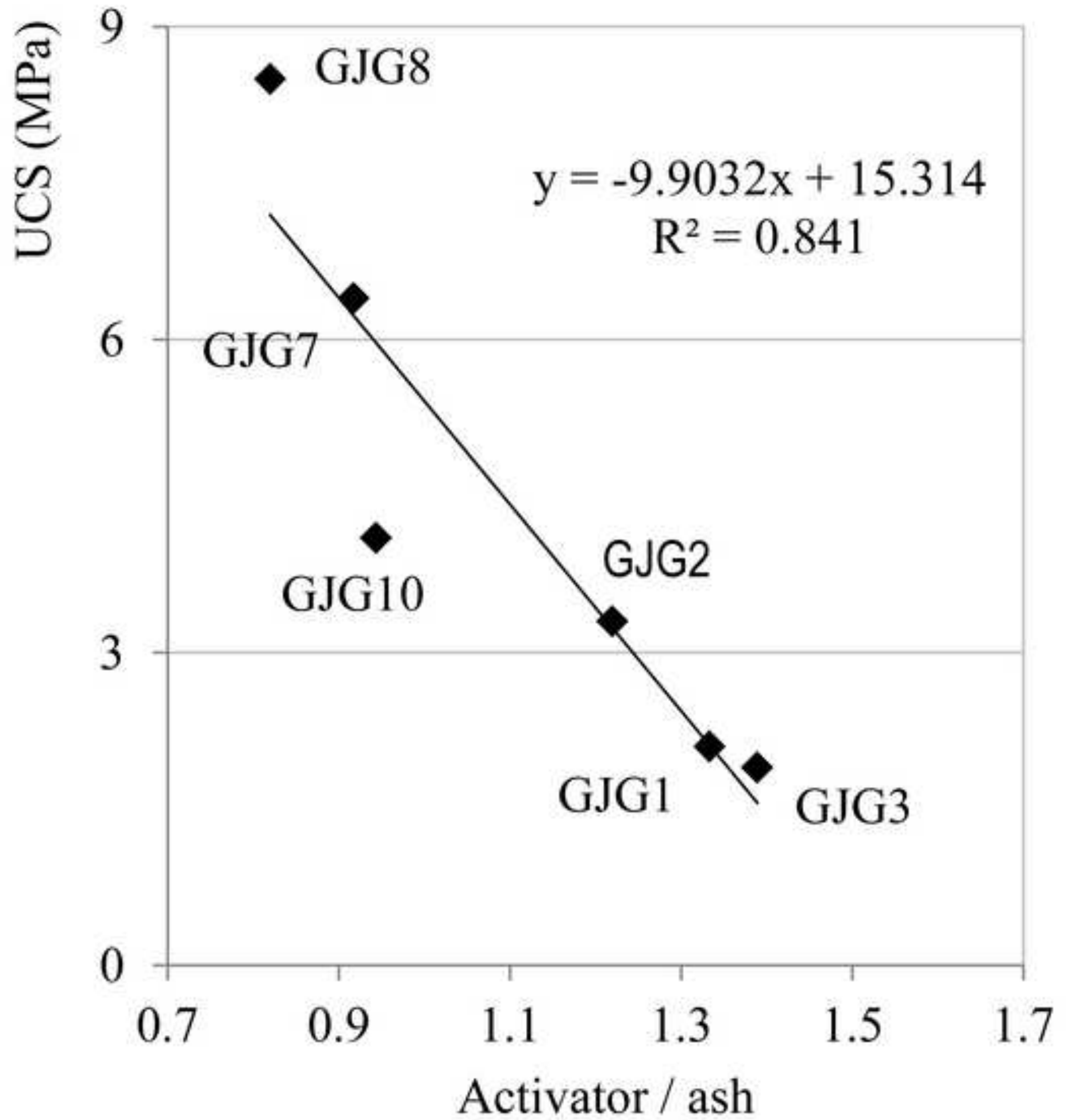


Figure 13 ere to download high resolution image

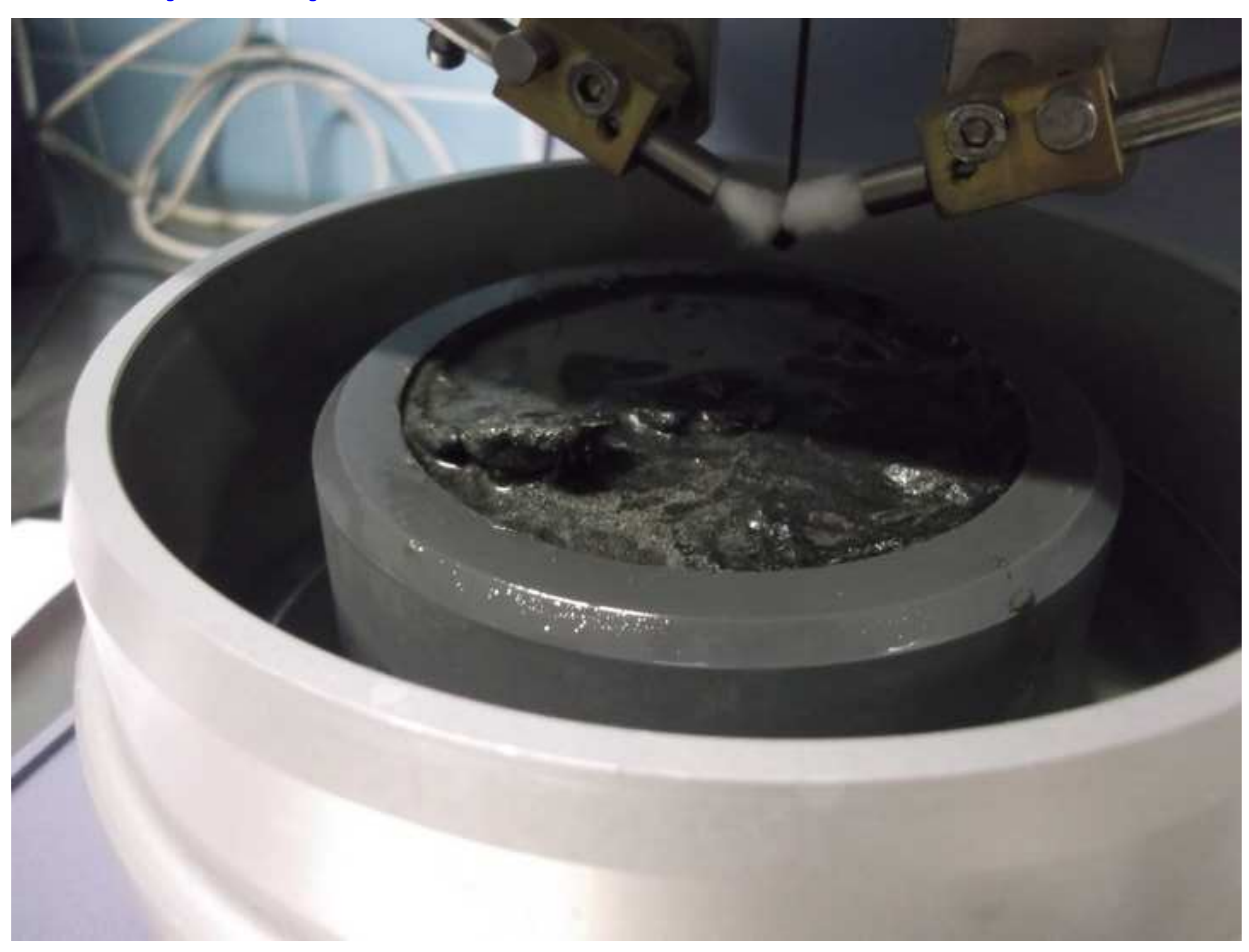

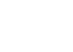
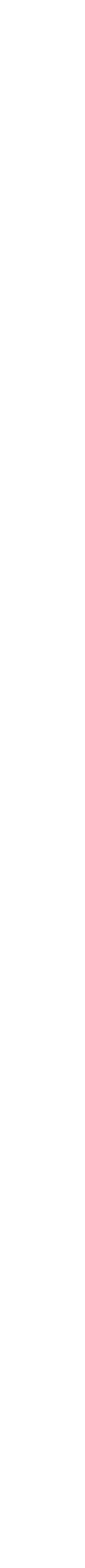
Figure $14 a$
Click here to download high resolution image

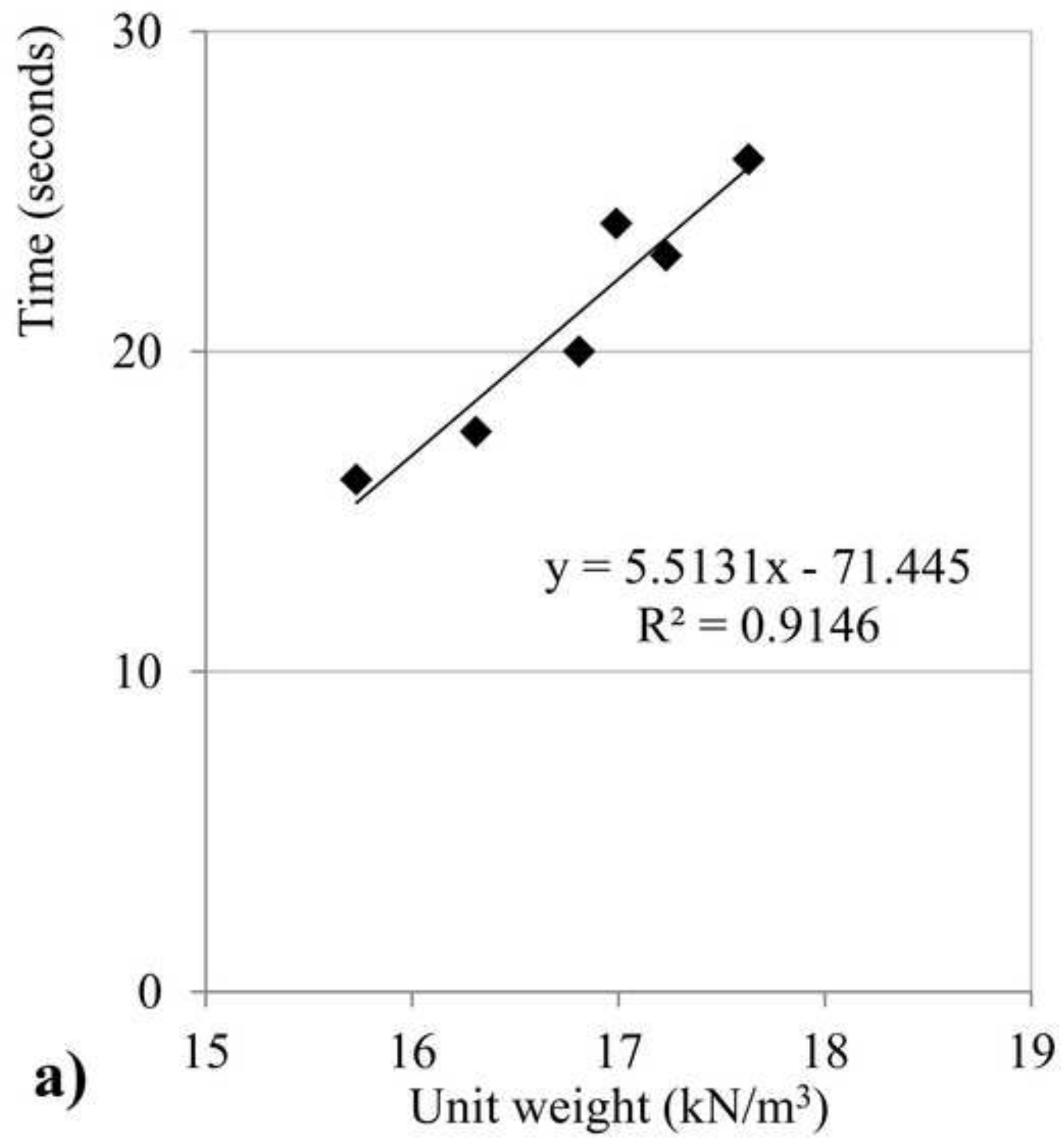


Figure $14 \mathrm{~b}$
Click here to download high resolution image

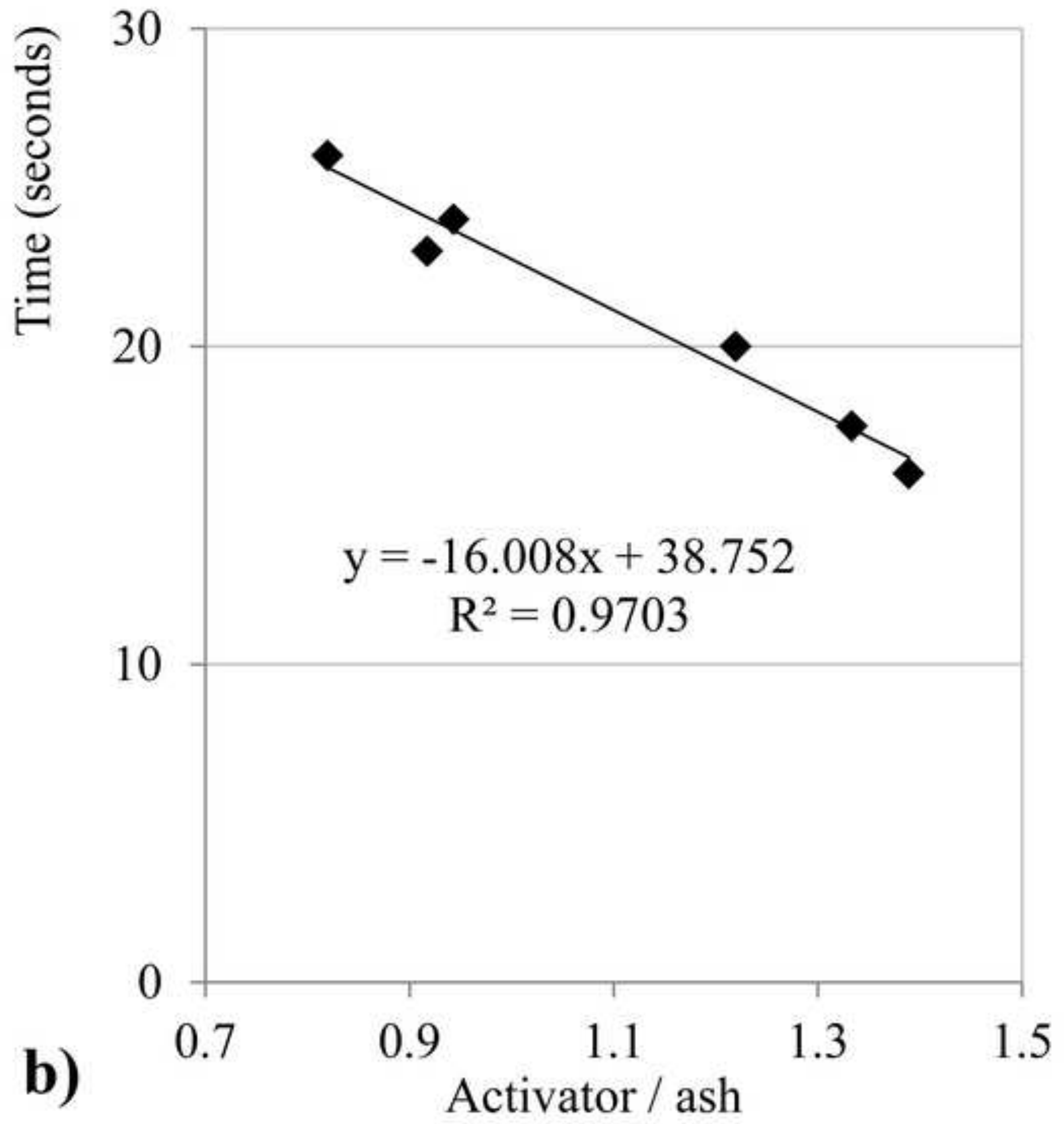


Figure $14 \mathrm{c}$
Click here to download high resolution image

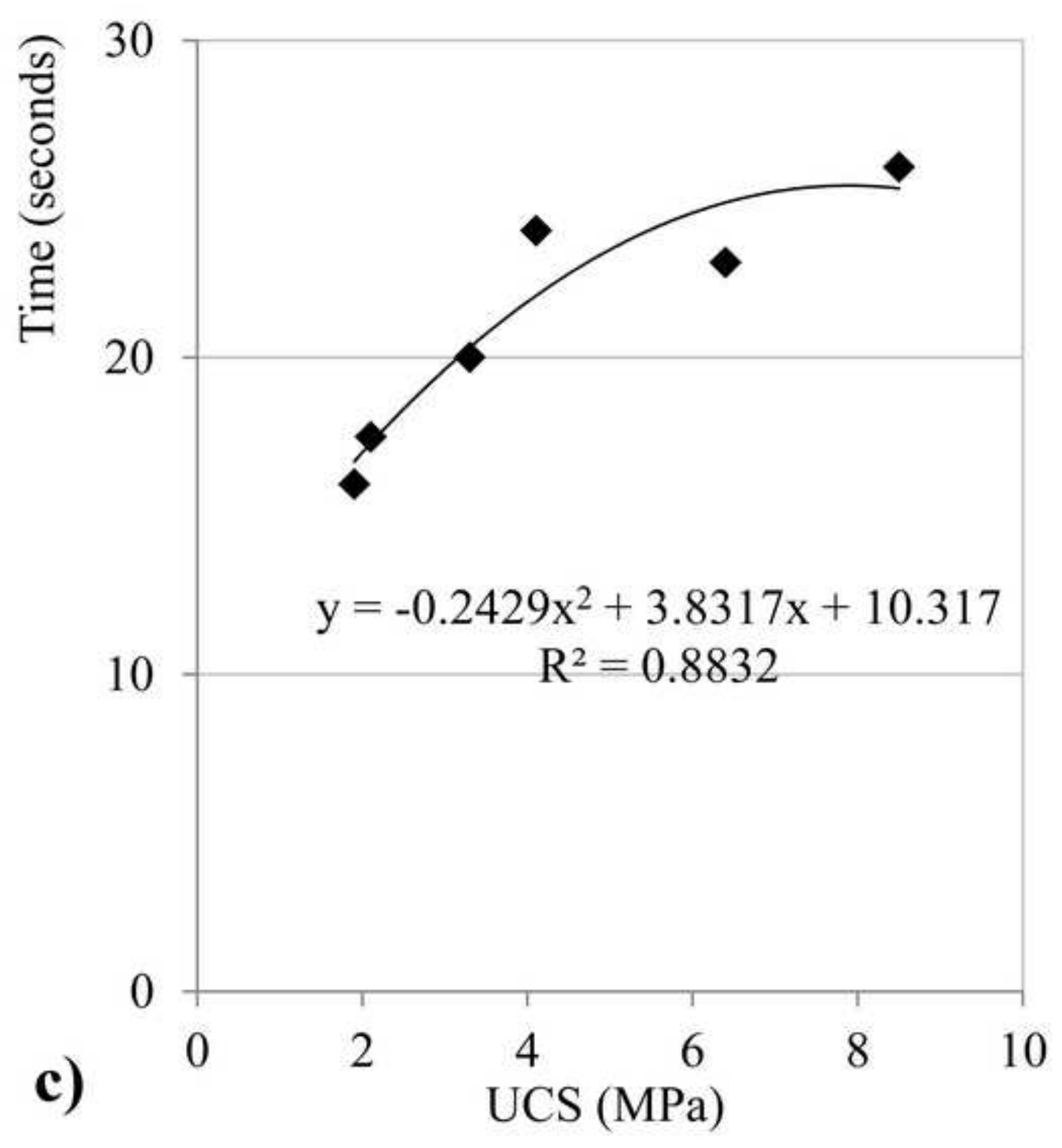


Click here to download high resolution image

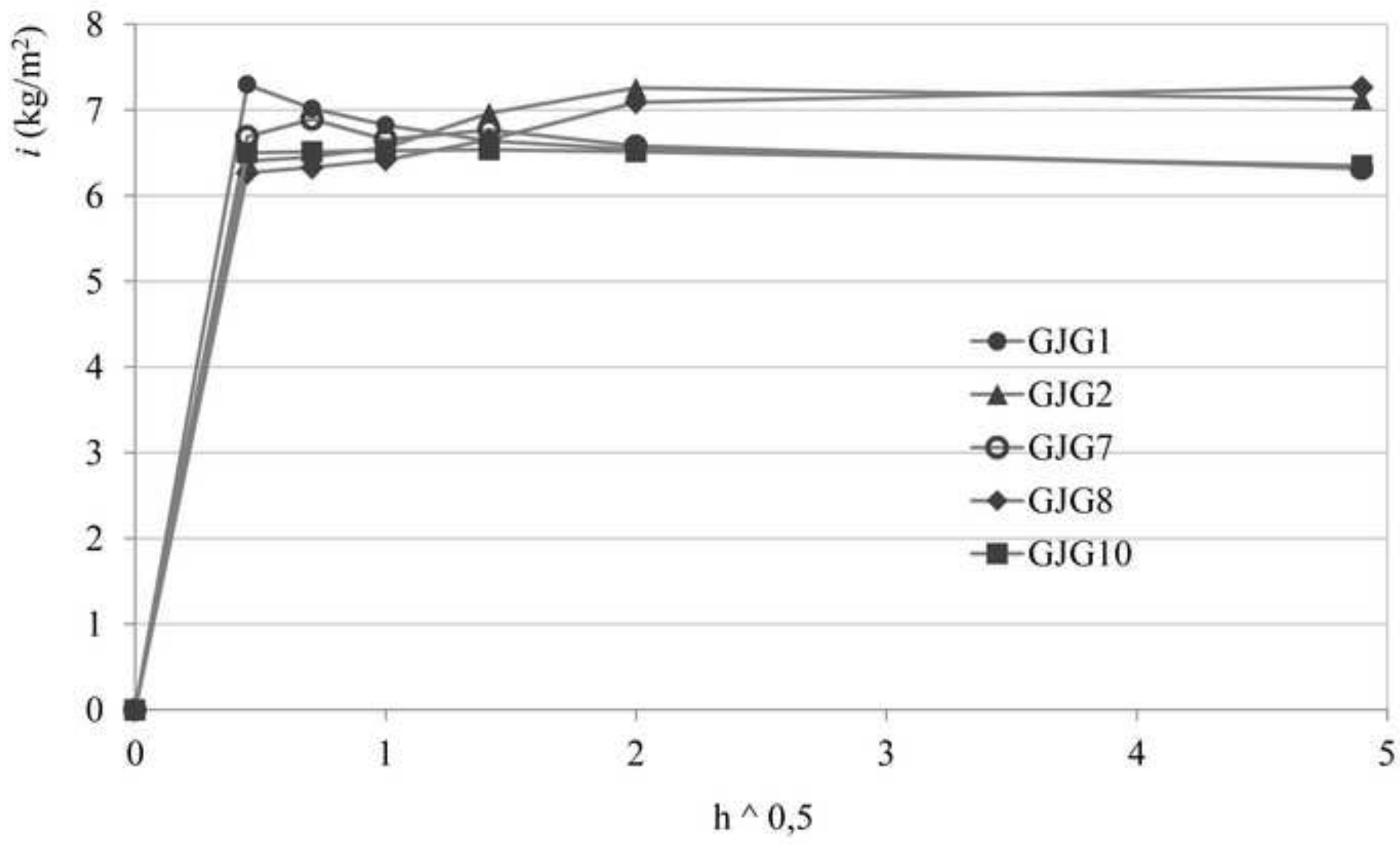


Click here to download high resolution image

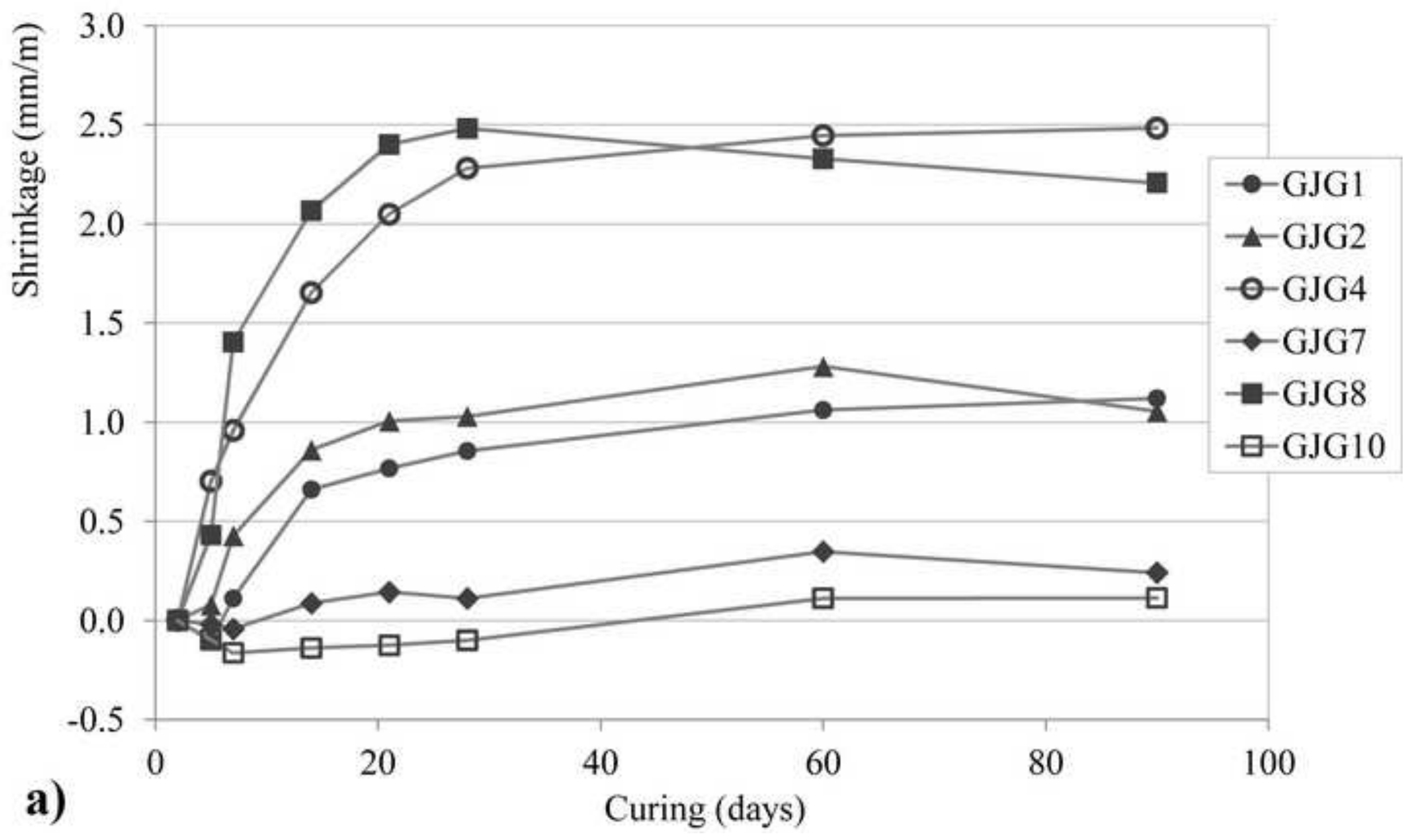




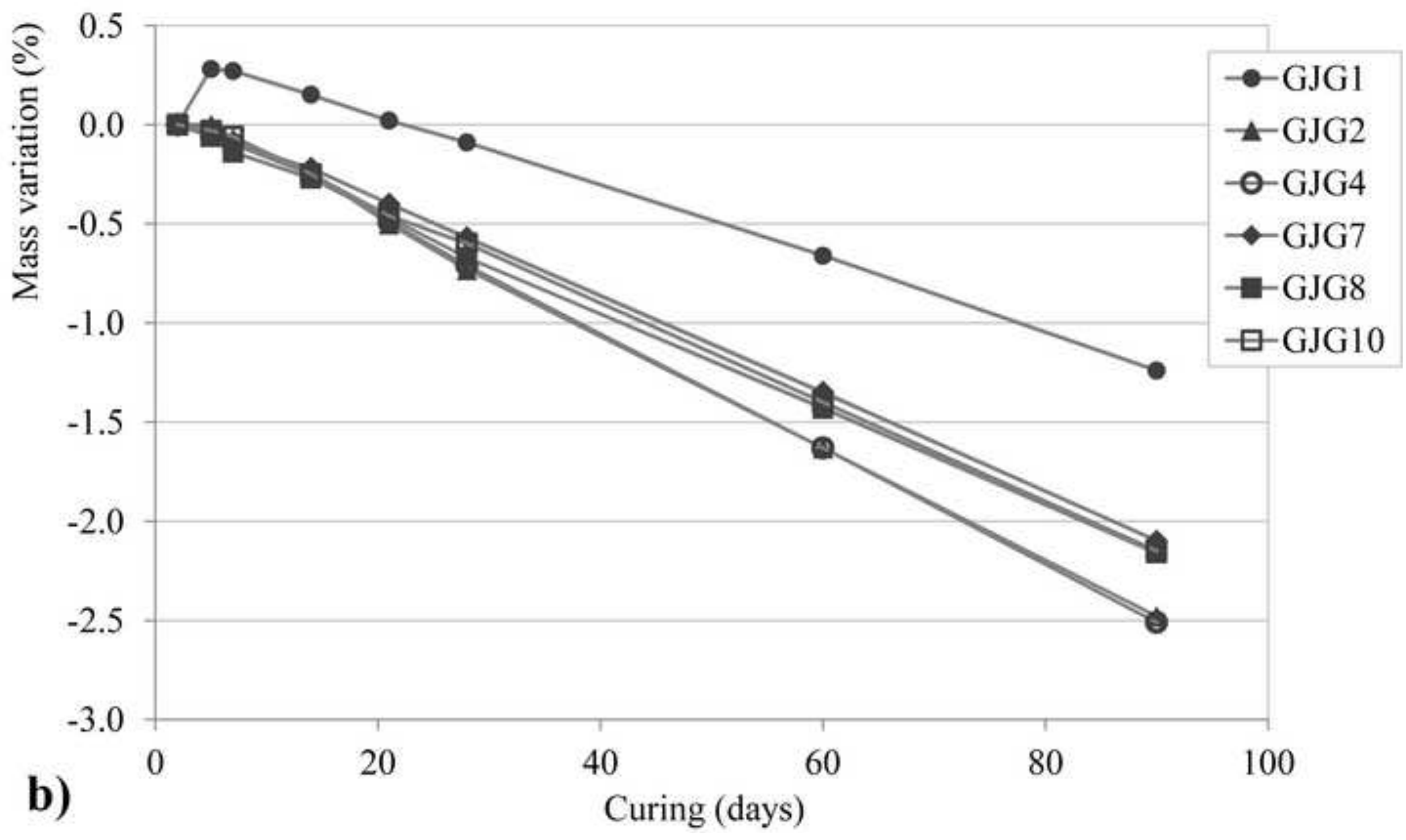


Click here to download high resolution image

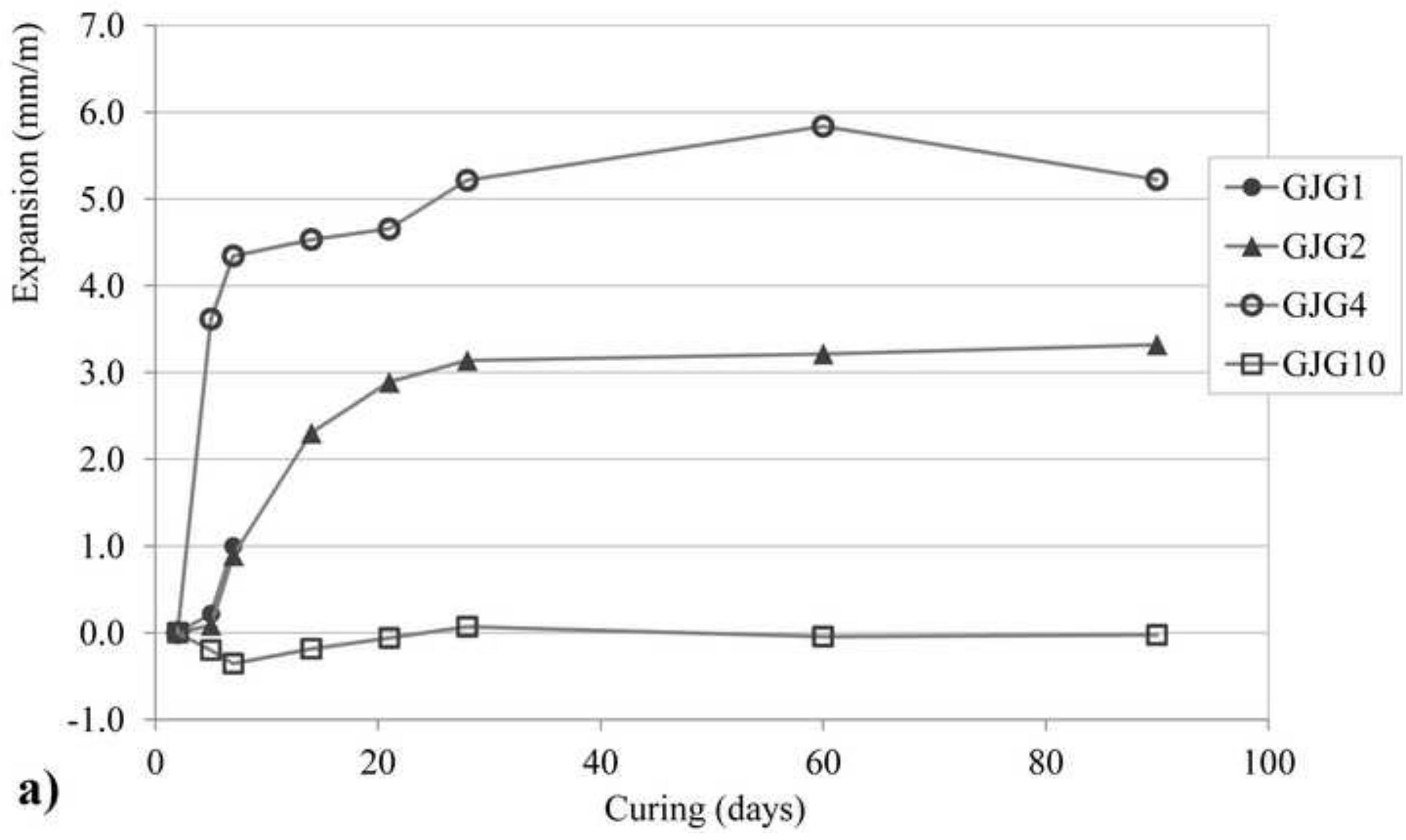


Click here to download high resolution image

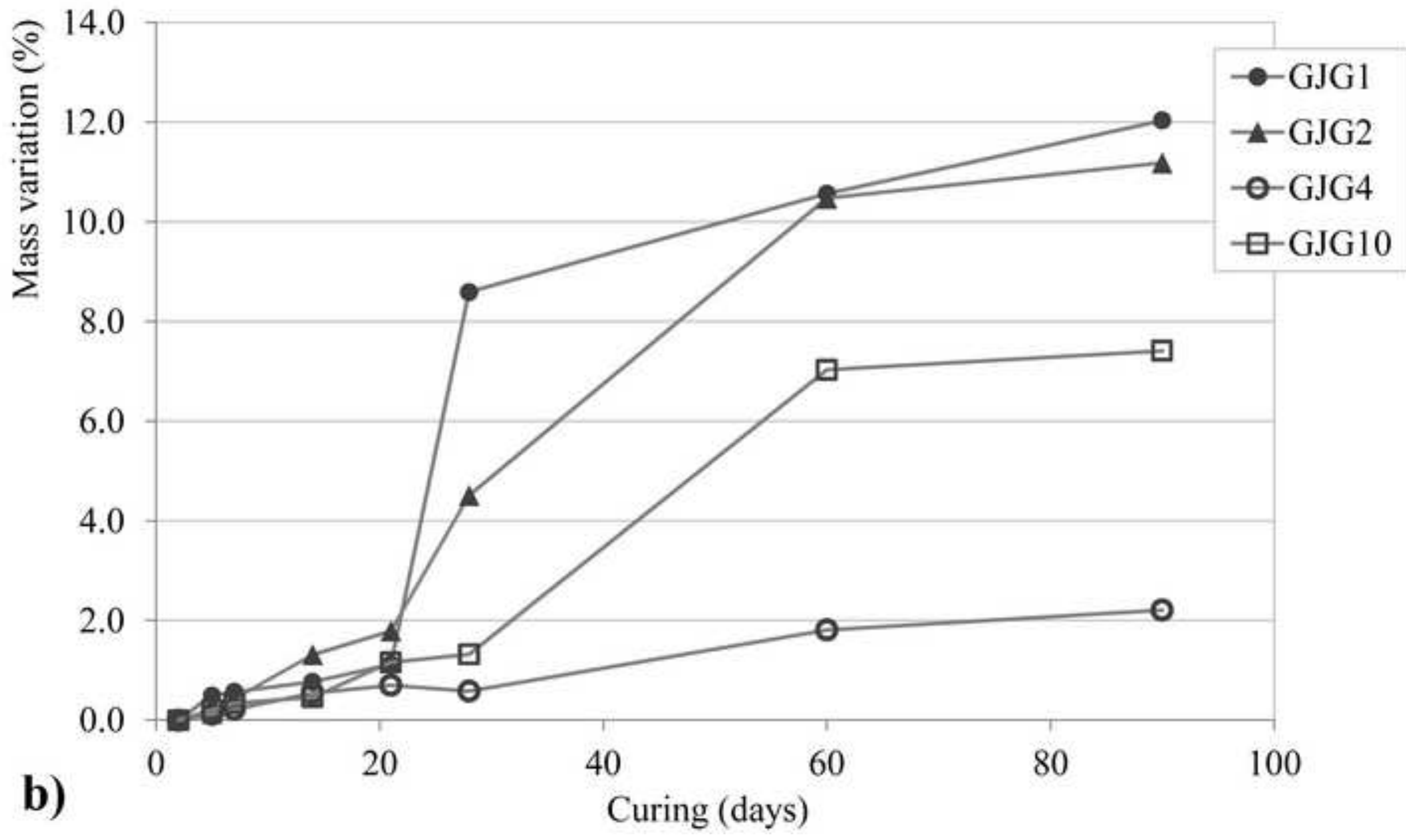


Figure 18
Click here to download high resolution image

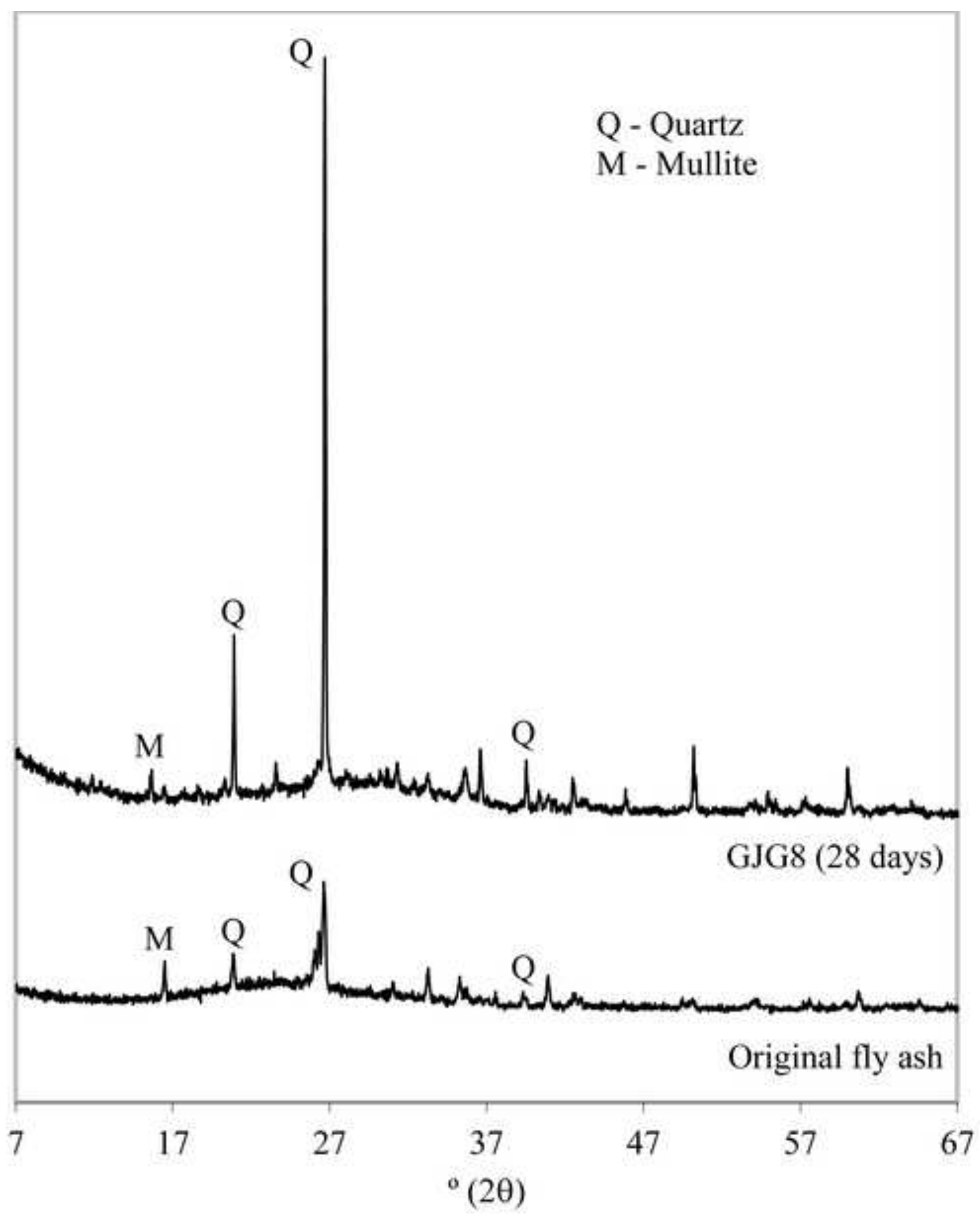

